\title{
Building State Capacity: Evidence from Biometric Smartcards in India*
}

\author{
Karthik Muralidharan ${ }^{\dagger}$ \\ UC San Diego
}

\author{
Paul Niehaus ${ }^{\ddagger}$ \\ UC San Diego
}

\author{
Sandip Sukhtankar ${ }^{\S}$ \\ Dartmouth College
}

August 24, 2014

\begin{abstract}
Anti-poverty programs in developing countries are often difficult to implement; in particular, many governments lack the capacity to deliver payments securely to targeted beneficiaries. We evaluate the impact of biometrically-authenticated payments infrastructure ("Smartcards") on beneficiaries of employment (NREGS) and pension (SSP) programs in the Indian state of Andhra Pradesh, using a large-scale experiment that randomized the rollout of Smartcards over 158 subdistricts and 19 million people. We find that, while far from perfectly implemented, the new system delivered a faster, more predictable, and less corrupt NREGS payments process without adversely affecting program access. For each of these outcomes, treatment group distributions first-order stochastically dominated those of the control group. The investment was cost-effective, as time savings to NREGS beneficiaries alone were equal to the cost of the intervention, and there was also a significant reduction in the "leakage" of funds between the government and beneficiaries. We also find evidence of improvements for pension beneficiaries, but these were typically not significant. Beneficiaries overwhelmingly preferred the new system for both NREGS and SSP programs. Overall, our results suggest that investing in secure payments infrastructure can significantly enhance "state capacity" to implement welfare programs in developing countries.
\end{abstract}

JEL codes: D73, H53, O30, O31

Keywords: state capacity, corruption, service delivery, biometric authentication, secure payments, electronic benefit transfers, public programs, NREGS, pensions, India

*We thank Santosh Anagol, Abhijit Banerjee, Gordon Dahl, Rema Hanna, Gordon Hanson, Erzo Luttmer, Santhosh Mathew, Simone Schaner, Monica Singhal, Anh Tran, and seminar participants at AEA 2013 meetings, Boston University, Stanford, IGC growth week-LSE, Harvard, UC San Diego, Duke, UConn, Dartmouth, Brown, CGD, Georgetown, ISI-Delhi, UC Berkeley, the World Bank, MIT, BREAD, and UPenn-CASI for comments and suggestions. We are grateful to officials of the Government of Andhra Pradesh, including Reddy Subrahmanyam, Koppula Raju, Shamsher Singh Rawat, Raghunandan Rao, G Vijaya Laxmi, AVV Prasad, Kuberan Selvaraj, Sanju, Kalyan Rao, and Madhavi Rani; as well as Gulzar Natarajan for their continuous support of the Andhra Pradesh Smartcard Study. We are also grateful to officials of the Unique Identification Authority of India (UIDAI), including Nandan Nilekani, Ram Sevak Sharma, and R Srikar for their support. We thank Tata Consultancy Services (TCS) and Ravi Marri, Ramanna, and Shubra Dixit for their help in providing us with administrative data. This paper would not have been possible without the outstanding efforts and inputs of the J-PAL/IPA project team, including Vipin Awatramani, Kshitij Batra, Prathap Kasina, Piali Mukhopadhyay, Michael Kaiser, Raghu Kishore Nekanti, Matt Pecenco, Surili Sheth, and Pratibha Shrestha. We are deeply grateful to the Omidyar Network - especially Jayant Sinha, CV Madhukar, Surya Mantha, Ashu Sikri, and Dhawal Kothari - for the financial support and long-term commitment that made this study possible. We also thank IPA, Yale University, and the Bill and Melinda Gates Foundation for additional financial support through the Global Financial Inclusion Initiative.

${ }^{\dagger}$ UC San Diego, JPAL, NBER, and BREAD. kamurali@ucsd.edu.

‡UC San Diego, JPAL, NBER, and BREAD. pniehaus@ucsd.edu.

${ }^{\S}$ Dartmouth College, JPAL, and BREAD. sandip.sukhtankar@dartmouth.edu. 


\section{Introduction}

Developing countries spend billions of dollars annually on anti-poverty programs, but the delivery of these programs is often poor and plagued by high levels of corruption (World Bank, 2003; Pritchett, 2010). Nevertheless, governments often spend considerably more resources and attention on specific programs relative to public goods such as implementation capacity (Lizzeri and Persico, 2001; Mathew and Moore, 2011). While a recent theoretical literature has highlighted the importance of investing in state capacity for economic development (Besley and Persson, 2009, 2010), there is limited empirical evidence on the returns to such investments.

One key constraint in the effective implementation of anti-poverty programs is the lack of a secure payments infrastructure to make transfers to intended beneficiaries. Often, money meant for the poor is simply stolen by officials along the way, with case studies estimating "leakage" of funds as high as 70 to 85 percent (Reinikka and Svensson, 2004; PEO, 2005). Thus, building a secure payments infrastructure can be seen as an investment in state capacity that both improves the implementation of existing anti-poverty programs, and also expands the state's long-term policy choice set.1

Recent technological advances have made it feasible to provide people with a biometricallyauthenticated unique ID linked to bank accounts, which can be used to directly transfer benefits. Biometric technology is especially promising in developing country settings where high illiteracy rates constrain financial inclusion by precluding the universal deployment of traditional forms of authentication, such as passwords or PIN numbers $4^{2}$ The potential for such payment systems to improve the performance of public welfare programs (and also provide financial inclusion for the poor) has generated enormous interest around the world, with a recent survey documenting the existence of 230 programs in over 80 countries that are deploying biometric identification and payment systems (Gelb and Clark, 2013). This enthusiasm is exemplified by India's ambitious Aadhaar initiative to provide biometric-linked unique IDs (UIDs) to nearly a billion residents, and then transition social program payments to Direct Benefit Transfers via UID-linked bank accounts. Over 600 million UIDs have been issued to date, with the former Finance Minister claiming that the project would be "a game changer for governance" (Harris, 2013).

At the same time, there are several reasons to be skeptical about the hype around these new payment systems. First, their implementation entails solving a complex mix of technical and logistical challenges, raising the concern that the undertaking might fail unless all

\footnotetext{
${ }^{1}$ For instance, the ability to securely transfer income to poor households may enable governments to replace distortionary subsidies with equivalent income transfers (which may not otherwise be feasible).

2 Fujiwara (2013) provides analogous evidence from Brazil on the effectiveness of electronic voting technology in circumventing literacy constraints, and on increasing enfranchisement of less educated voters.
} 
components are well-implemented (Kremer, 1993). Second, vested interests whose rents are threatened may subvert the intervention and limit its effectiveness Krusell and Rios-Rull, 1996; Prescott and Parente, 2000). Third, the new system could generate exclusion errors if genuine beneficiaries are denied payments due to technical problems. This would be particularly troubling if it disproportionately hurt the most vulnerable beneficiaries (Khera, 2011). Fourth, reducing corruption could paradoxically hurt the poor if it dampened incentives for officials to implement anti-poverty programs in the first place (Leff, 1964). Finally, even assuming positive impacts, cost-effectiveness is unclear as the best available estimates depend on a number of untested assumptions (see e.g. NIPFP (2012)). Overall, there is very limited evidence to support either the enthusiasts or the skeptics of biometric payment systems.

In this paper, we contribute toward filling this gap, by presenting evidence from a largescale experimental evaluation of the impact of rolling out biometric payments infrastructure to make social welfare payments in India. Working with the Government of the Indian state of Andhra Pradesh (AP) $]^{3}$ we randomized the order in which 158 sub-districts introduced a new "Smartcard" program for making payments in two large welfare programs: the National Rural Employment Guarantee Scheme (NREGS), and Social Security Pensions (SSP). NREGS is the largest workfare program in the world (targeting 800 million rural residents in India), but has well-known implementation issues including leakage and problems with the payment process (Niehaus and Sukhtankar, 2013a b; Dutta et al., 2012). SSP programs complement NREGS by providing income support to the rural poor who are not able to work (Dutta et al., 2010). The new Smartcard-based payment system used a network of locally-hired, bank-employed staff to biometrically authenticate beneficiaries and make lastmile cash payments. It thus provided beneficiaries of NREGS and SSP programs with the same effective functionality as intended by UID-linked Direct Benefit Transfers.

The experiment randomized the rollout of Smartcards over a universe of about 19 million people, with randomization conducted over entire sub-districts, making it (to our knowledge) the largest randomized controlled trial ever conducted. Evaluating an "as is" deployment of a complex program that was implemented at scale by a government addresses one common concern about randomized trials in developing countries: that studying NGO-led pilots may not provide accurate forecasts of performance at scales relevant for policy-making (see for example Banerjee et al. (2008); Acemoglu (2010); Bold et al. (2013)). The experiment thus provides an opportunity to learn about the likely impacts of India's massive UID initiative, as well as scaled-up deployments of biometric payments infrastructure more generally.

After two years of program rollout, the share of Smartcard-enabled payments across both programs in treated sub-districts had reached around 50\%. This conversion rate over two

\footnotetext{
${ }^{3}$ The original state of AP (with a population of 85 million) was divided into two states on June 2, 2014. Since this division took place after our study, we use the term AP to refer to the original undivided state.
} 
years compares favorably to the pace of electronic benefit transfer rollout in other contexts. For example, the United States took over 15 years to convert all Social Security payments to electronic transfers. On the other hand, the inability to reach a $100 \%$ conversion rate (despite the stated goal of senior policymakers to do so) reflects the non-trivial logistical, administrative, and political challenges of rolling out a complex new payment system (see section 3.3 and Mukhopadhyay et al. (2013) for details).

We therefore focus throughout the paper on intent-to-treat analysis, which correctly estimates the average return to as-is implementation following the "intent" to implement the new system. These estimates yield the relevant policy parameter of interest, because they reflect the impacts that followed a decision by senior government officials to invest in the new payments system and are net of all the logistical and political economy challenges that accompany such a project in practice.

We find that, though incompletely implemented, Smartcards delivered a faster, more predictable, and less corrupt payment process for beneficiaries, especially under the NREGS program. NREGS workers spent 21 fewer minutes collecting each payment (19\% less than the control group), and collected their payments 10 days sooner after finishing their work ( $29 \%$ faster than the control mean). The absolute deviation of payment delays also fell by $39 \%$ relative to the control group, suggesting that payments became more predictable. Payment collection times for SSP beneficiaries also fell, but the reduction was small and statistically insignificant.

Turning to payment amounts, we find that household NREGS income in treated areas increased by $24 \%$. However, government outlays on NREGS did not change, resulting in a significant reduction in leakage of funds between the government and target beneficiaries. Household SSP income in treated areas increased by $6 \%$, with no corresponding change in government outlays, resulting in a reduction in SSP leakage as well $(p=0.11)$.

We find no evidence that poor or vulnerable segments of the population were made worse off by the new system. For key outcomes such as the time to collect payments, payment delays, and payments received, treatment distributions first-order stochastically dominate control distributions. Thus, no treatment household was worse off relative to a control household at the same percentile of the outcome distribution. Treatment effects also did not vary significantly as a function of village-level baseline characteristics, suggesting broadbased gains from access to the new payments system.

These gains for participants on the intensive margin of program performance were not offset by reduced access to programs on the extensive margin. We find that the proportion of households reporting having worked on NREGS increased by 7.4 percentage points (an $18 \%$ increase over the control mean of $42 \%$ ). We show that this result is explained by a significant reduction in the fraction of "quasi-ghost" beneficiaries - defined as cases where 
officials reported work against a beneficiary's name and claimed payments for this work, but where the beneficiary received neither work nor payments. These results suggest that the introduction of biometric authentication made it more difficult for officials to over-report the amount of work done (and siphon off the extra wages unknown to the beneficiary), and that the optimal response for officials was to ensure that more actual work was done against the claimed wages, with a corresponding increase in payments made to workers.

To better understand the mechanism of impact, we conduct a non-experimental decomposition of the treatment effects. We find that improvements in the timeliness of payments are concentrated entirely in villages that switched to the new payment system, but do not vary across recipients who had or had not received biometric Smartcards within these villages. In contrast, increases in payments to beneficiaries and reductions in leakage are concentrated entirely among recipients who actually received biometric Smartcards. This suggests that organizational changes associated with the new payment system (especially moving the point of payment to the village) drove improvements in the payments process, while biometric authentication was key to reducing fraud.

Overall, the data suggest that Smartcards improved beneficiary experiences in collecting payments, increased payments received by program participants, reduced corruption, broadened access to program benefits, and achieved these without substantially altering fiscal burdens on the state. Consistent with these findings, $90 \%$ of NREGS beneficiaries and $93 \%$ of SSP recipients who experienced Smartcard-based payments reported that they prefer the new system to the old.

Finally, Smartcards appear to be cost-effective. In the case of NREGS, our best estimate of the value of beneficiary time savings ( $\$ 4.3$ million) alone exceeds the government's cost of program implementation and operation (\$4.1 million). Further, our estimated NREGS leakage reduction of $\$ 32.8$ million/year is eight times greater than the cost of implementing the new Smartcard-based payment system. The reduction in leakage represents a redistribution from corrupt officials to beneficiaries, and is hence not a Pareto improvement. However, if a social planner places a greater weight on the gains to program beneficiaries (who are likely to be poorer) than on the loss of illegitimate rents to corrupt officials, the welfare effects of reduced leakage will be positive.

The first contribution of our paper is as an empirical complement to the recent theoretical work on state capacity (Besley and Persson, 2009, 2010). Despite the high potential social returns to investing in public goods such as general-purpose implementation capacity, both theory and evidence suggest that politicians may underinvest in these relative to specific programs that provide patronage to targeted voter and interest groups (Lizzeri and Persico, 2001; Mathew and Moore, 2011). Further, politicians may perceive the returns to such investments as accruing in the long-run, while their own electoral time horizon may be 
shorter. Our results suggest that in settings of weak governance, the returns to investing in improved implementation capacity can be positive and large over as short a time horizon as two years, $4^{4}$

We also contribute to the literature on identifying effective ways to reduce corruption in developing countries (Olken, 2007; Reinikka and Svensson, 2005). Our results highlight the potential for technology-enabled top-down improvements in governance to reduce corruption, and may also help to clarify the literature on technology and service delivery in developing countries, where an emerging theme is that technology may or may not live up to its hype. Duflo et al. (2012) find, for example, that digital cameras and monetary incentives increased teacher attendance and test scores in Indian schools (when implemented in schools run by an NGO). Banerjee et al. (2008) find, on the other hand, that a similar initiative to monitor nurses in health care facilities was subverted by vested interests when a successful NGOinitiated pilot program was transitioned to being implemented by the local government. Our results, which describe the effects of an intervention driven from the start by the government's own initiative, suggest that technological solutions can significantly improve service delivery when implemented as part of an institutionalized policy decision to do so at scale.

Finally, our results complement a growing literature on the impact of payments and authentication infrastructure in developing countries. Jack and Suri (2014) find that the MPESA mobile money transfer system in Kenya improved risk-sharing; Aker et al. (2013) find that using mobile money to deliver transfers in Niger cut costs and increased women's intra-household bargaining power; and Gine et al. (2012) show how biometric authentication helped a bank in Malawi reduce default and adverse selection.

From a policy perspective, our results contribute to the ongoing debates in India and other developing countries regarding the costs and benefits of using biometric payments technology for service delivery, and the legal and political implications of doing so. We discuss the policy implications of our results and caveats to external validity in the conclusion.

The rest of the paper is organized as follows. Section 2 describes the context, social programs, and the Smartcard intervention. Section 3 describes the research design, data, and implementation details. Section 4 presents our main results. Section 5 discusses costeffectiveness. Section 6 concludes.

\footnotetext{
${ }^{4}$ While set in a different sector, the magnitude of our estimated reduction in leakage is consistent with recent evidence from India showing that investing in better monitoring of teachers may yield a tenfold reduction in the cost of teacher absence (Muralidharan et al., 2014). Dal Bó et al. (2013) present complementary evidence on the impact of raising public sector salaries on the quality of public sector workers hired.
} 


\section{Context and Intervention}

As the world's largest democracy, India has sought to reduce poverty through ambitious welfare schemes. Yet these schemes are often poorly implemented (Pritchett, 2010) and prone to high levels of corruption or "leakage" as a result (PEO, 2005; Niehaus and Sukhtankar, $2013 \mathrm{a}$ b). Benefits that do reach the poor arrive with long and variable lags and are timeconsuming for recipients to collect. The AP Smartcard Project aimed to address these problems by integrating new payments infrastructure into two major social welfare programs managed by the Department of Rural Development, which serve as a comprehensive safety net for both those able (NREGS) and unable (SSP) to work. We next describe these programs and how the introduction of Smartcards altered their implementation.

\subsection{The National Rural Employment Guarantee Scheme}

The NREGS is one of the two main welfare schemes in India and the largest workfare program globally, covering $11 \%$ of the world's population. The Government of India's allocation to the program for fiscal year April 2013-March 2014 was Rs. 330 billion (US $\$ 5.5$ billion), or $7.9 \%$ of its budget.5 The program guarantees every rural household 100 days of paid employment each year. There are no eligibility requirements, as the manual nature of the work is expected to induce self-targeting.

Participating households obtain jobcards, which list household members and have empty spaces for recording employment and payment. Jobcards are issued by the local Gram Panchayat (GP, or village) or mandal (sub-district) government offices. Workers with jobcards can apply for work at will, and officials are legally obligated to provide either work on nearby projects or unemployment benefits (though in practice the latter are rarely provided). NREGS projects vary somewhat but typically involve minor irrigation work or improvement of marginal lands. Project worksites are managed by officials called Field Assistants, who record attendance and output on "muster rolls" and send these to the sub-district for digitization, from where the work records are sent up to the state level, which triggers the release of funds to pay workers.

Figure A.17 depicts the payment process in AP prior to the introduction of Smartcards. The state government transfers money to district offices, which pass the funds to mandal offices, which transfer it to beneficiary post office savings accounts. Workers withdraw funds by traveling to branch post offices, where they establish identity using jobcards and passbooks. In practice it is said to be common for workers (especially illiterate ones) to give their documents to the Field Assistant who then controls and operates their accounts - taking

${ }^{5}$ NREGS figures: http://indiabudget.nic.in/ub2013-14/bag/bag5.pdf total outlays: http:// indiabudget.nic.in/ub2013-14/bag/bag4.pdf 
sets of passbooks to the post office, withdrawing cash in bulk, and returning to distribute it in the villages.

By design, the volume of NREGS work and payments should theoretically be constrained only by worker demand. In practice, supply increasingly appears to be the binding constraint, with NREGS availability being constrained by both the level of budgetary allocations, and by limited local administrative capacity and willingness to implement projects (Dutta et al. 2012; Witsoe, 2014). We confirm this in our data, and find that less than $4 \%$ of workers in our control group report that they can access NREGS work whenever they want it (Table 5). Further, both field reports and data from our control group (Table 2) suggest that even conditional on doing NREGS work, the payment process is slow and unreliable, limiting the extent to which the NREGS can effectively insure the rural poor ${ }^{6}$ In extreme cases, delayed payments have reportedly led to worker suicides (Pai, 2013).

The payments process is also vulnerable to leakage of two forms: over-reporting or underpayment. Consider a worker who has earned Rs. 100, for example: the Field Assistant might report that he is owed Rs. 150 but pay the worker only Rs. 90, pocketing Rs. 50 through over-reporting and Rs. 10 through under-payment. Two extreme forms of overreporting are "ghost" workers who do not exist, but against whose names work is reported and payments are made; and "quasi-ghost" workers who do exist, but who have not received any work or payments though work is reported against their names and payments are made. In both cases, the payments are typically siphoned off by officials. Prior work in the same context suggests that over-reporting is the most prevalent form of leakage - perhaps because it involves stealing from a "distant" taxpayer, and can be done without the knowledge of workers (Niehaus and Sukhtankar, 2013a).

\subsection{Social Security Pensions}

Social Security Pensions are unconditional monthly payments targeted to vulnerable populations. The program covers over 6 million beneficiaries and costs the state roughly Rs. 18 billion (\$360 million) annually. Eligibility is restricted to members of families classified as Below the Poverty Line (BPL) who are residents of the district in which they receive their pension and not covered by any other pension scheme. In addition, recipients must qualify in one of four categories: old age ( $>65)$, widow, disabled, or certain displaced traditional occupations. Pension lists are proposed by village assemblies (Gram Sabhas) and sanctioned by the mandal administration. Pensions pay Rs. $200(\sim \$ 3)$ per month except for disability

\footnotetext{
${ }^{6}$ Imperfect implementation of social insurance programs may even be a deliberate choice by local elites to preserve their power over the rural poor, as they are often the default providers of credit and insurance. See Anderson et al. (2013) for discussion, and also Jayachandran (2006) who shows how uninsured rainfall shocks benefit landlords and hurt workers (especially those who lack access to credit).
} 
pensions, which pay Rs. $500(\sim \$ 8)$.

Unlike the NREGS, pension payments are typically disbursed each month in the village itself by a designated village development officer. While we are not aware of any systematic data on payment delays or leakage from the SSP prior to our own study, press reports have documented cases of "ghost" beneficiaries (for example, deceased beneficiaries who were not removed from the roster) and cases of officials taking bribes to enroll beneficiaries or to disburse payments (Mishra, 2005; Sethi, 2014). Our own data below suggest that a form of "over-reporting" also exists in which officials tell beneficiaries they are eligible for the smaller Rs. 200 pension while claiming Rs. 500 on their behalf.

\subsection{Smartcard-enabled Payments and Potential Impacts}

The Smartcard project was India's first large-scale attempt to implement a biometric payments system.7 It modified the pre-existing NREGS and SSP payment systems in two ways. First, it required beneficiaries to establish their identity using biometrics before collecting payments. Biometric data (typically all ten fingerprints) and digital photographs were collected during enrollment campaigns and linked to newly created bank accounts. Beneficiaries were then issued a physical "Smartcard" that included their photograph and (typically) an embedded electronic chip storing biographic, biometric, and bank account details. Beneficiaries use these cards to collect payments as follows: (a) they insert them into a Point-of-Service device operated by a Customer Service Provider (CSP), which reads the card and retrieves account details; (b) the device prompts for one of ten fingers, chosen at random, to be scanned; (c) the device compares this scan with the records on the card, and authorizes a transaction if they match; (d) the amount of cash requested is disbursed 8 and (e) the device prints out a receipt (and in some cases even announces transaction details in the local language, Telugu). Figure A.2 shows a typical Smartcard and a fingerprint scan in progress. 9

Second, the intervention changed the identities of the people and organizations responsible for delivering payments. Organizationally, the government contracted with banks to manage payments, and these banks in turn contracted with Technology Service Providers (TSPs) to

\footnotetext{
${ }^{7}$ The central (federal) government had similar goals for the Aadhaar (UID) platform. However, Aadhaar is purely an enabling infrastructure that had not yet been integrated into any of the major welfare schemes as of June 2014. The Smartcard intervention can therefore be seen as a functional precursor to the integration of Aadhaar into the NREGS and SSP.

${ }^{8}$ While beneficiaries could in principle leave balances on their Smartcards and thus use them as savings accounts, NREGS guidelines required beneficiaries to be paid in full for each spell of work. As a result the default expectation was that workers would withdraw their wages in full.

${ }^{9}$ Note that a truly "smart" card was not required or always issued: one Bank chose to issue paper cards with digital photographs and bar codes while storing biometric data in the Point-of-Service device. Authentication in this system was otherwise the same.
} 
manage the last-mile logistics of delivery; the TSPs then hired and trained CSPs. ${ }^{10}$ Figure A.1b illustrates the flow of funds from the government through banks, TSPs and CSPs to beneficiaries under this scheme. The government assigned each district to a single bank-TSP pairing, and compensated them with a $2 \%$ commission on all payments delivered in GPs that were migrated to the new Smartcard-based payment system (banks and TSPs negotiated their own terms on splitting the commission) ${ }^{11}$ The government required a minimum of $40 \%$ beneficiaries in a GP to be enrolled and issued Smartcards prior to converting the GP to the new payment system. Once a GP was "converted", all payments in that GP were routed through the Bank-TSP-CSP system (even for beneficiaries who had not enrolled in or obtained Smartcards).

The government also stipulated norms for CSP selection, and required that CSPs be women resident in the villages they served, have completed secondary school, not be related to village officials, preferably be members of historically disadvantaged castes, and be members of a self-help group 12 While meeting all these requirements was often difficult and sometimes impossible, the selected CSPs were typically closer socially to beneficiaries than the postoffice officials or village development officers (both government employees) who previously disbursed payments. Moreover, because CSPs were stationed within villages they were also geographically closer to beneficiaries.

While the Smartcard intervention was designed to help beneficiaries, its impacts were nevertheless unclear a priori. Smartcards could speed up payments, for example, by moving transactions from the (typically distant) post office to a point within the village. They could just as easily slow down the process, however, if CSPs were less reliably present or if the checkout process were slower due to technical problems. Similarly, on-time cash availability could either improve or deteriorate depending on how well TSPs managed cash logistics relative to the post office. In a worst-case scenario the intervention could cut off payments to beneficiaries who were unable to obtain cards, lost their cards, or faced malfunctioning authentication devices. Skeptics of biometric authentication have emphasized such concerns (Khera, 2011) 13

Impacts on fraud and corruption were also unclear. In principle, Smartcards should reduce

\footnotetext{
${ }^{10}$ This structure reflects Reserve Bank of India (RBI) regulations requiring that accounts be created only by licensed banks. Since the fixed cost of bank branches was too high to make it viable to profitably serve rural areas, the RBI allows banks to partner with TSPs to jointly offer and operate no-frills accounts that could be used for savings, benefits transfers, remittances, and cash withdrawals.

${ }^{11}$ The long-term vision of the government (which was supported by the banks) was that these commissions would cover the fixed cost of setting up CSPs and cash management infrastructure, and reduce the marginal cost of providing financial services in rural areas.

${ }^{12}$ Self-help groups are groups of women organized by the government to facilitate micro-lending.

${ }^{13}$ The tension here between reducing fraud and excluding genuine beneficiaries is an illustration of the general trade-off between making Type I and Type II errors in public welfare programs. Adjudicating claims of disability insurance is a good example of a setting where reasonable people (including judges) can have different opinions as to how this trade-off should be resolved (Dahl et al., 2013).
} 
payments to "ghost" beneficiaries as ghosts do not have fingerprints, and also make it harder for officials to collect payments in the name of real beneficiaries as they must be present, provide biometric input, and receive a receipt which they can compare to the amount disbursed. These arguments assume, however, that the field technology works as designed and that CSPs are no more likely to be corrupt than local GP officials and post office workers. Moreover, truly eliminating leaks and closing off potential loopholes might require complete implementation, and yet the intervention was complex enough that complete implementation was unlikely.

Finally, even if Smartcards were to reduce corruption in payments, they could have negative consequences on the extensive margin of program access. In the case of NREGS, reducing rents may reduce local officials' incentives to create and implement projects, which could reduce participants' access to work. In the case of SSP, reducing leakage could drive up the illicit price of getting on the SSP beneficiary list in the first place.

\section{Research Design}

\subsection{Randomization}

The AP Smartcard project began in 2006, but took time to overcome initial implementation challenges including contracting, integration with existing systems, planning the logistics of enrollment and cash management, and developing processes for financial reporting and reconciliation. Because the government contracted with a unique bank to tackle these problems within each district, and because multiple banks participated, considerable heterogeneity in performance across districts emerged over time. In eight of twenty-three districts the responsible banks made no progress whatsoever, and in early 2010 the government decided to restart the program in these districts, re-allocating their contracts to banks that had implemented Smartcards in other districts. This "fresh start" created an attractive setting for an experimental evaluation of Smartcards, both because the roll-out of the intervention could be randomized but also because the most critical implementation challenges had already been solved in other districts.

Our evaluation was conducted in these eight districts, which have a combined rural population of around 19 million. While not randomly selected, they look similar to AP's remaining 15 districts on major socioeconomic indicators, including proportion rural, scheduled caste, literate, and agricultural laborers. They also span the state geographically, with representation in all three historically distinct socio-cultural regions: 2 in Coastal Andhra and 3 each in Rayalseema and Telangana. ${ }^{14}$

\footnotetext{
${ }^{14}$ The districts were Adilabad, Anantapur, Khammam, Kurnool, Nalgonda, Nellore, Vizianagaram, and
} 
The study was conducted under a formal agreement between J-PAL South Asia and the Government of Andhra Pradesh (GoAP) to randomize the order in which mandals (subdistricts) were converted to the Smartcard system. Mandals were assigned by lottery to one of three rollout waves: 113 to wave 1, 195 to wave 2, and 45 to wave 3 (Figure A.3).15 We focus on comparisons between outcomes in wave 1 (treatment) and wave 3 (control) mandals; wave 2 was created as a buffer to increase the time between program rollout in these waves. The lag between program rollout in treatment and control mandals was over two years. Randomization was stratified by district and by a principal component of socio-economic characteristics ${ }^{16}$ Table A.1 presents tests of equality between treatment and control mandals along characteristics used for stratification, none of which (unsurprisingly) differ significantly. Table A.2 reports balance along all of our main outcomes as well as key socio-economic household characteristics from the baseline survey; one of eighteen differences for NREGS and two of eleven for SSP are significant at the $10 \%$ level. In the empirical analysis we include specifications that control for the village-level baseline mean value of our outcomes to test for sensitivity to any chance imbalances.

\subsection{Data Collection}

Our data collection was designed to capture impacts broadly, including both anticipated positive and negative effects. We collected (a) official records on beneficiary lists and benefits paid; (b) baseline and endline household surveys of representative samples of enrolled participants; (c) independent audits of NREGS worksites; (d) surveys of village leaders to measure political, social, and development indicators; and (e) surveys of public officials to capture process and implementation issues. Household surveys included detailed questions on receipts from and participation in the NREGS and SSP as well as questions about general income, employment, consumption, and assets more generally. We conducted surveys in August through September of 2010 (baseline) and 2012 (endline) in order to obtain information about NREGS participation between May and July of those years, as this is the peak period

\footnotetext{
Kadapa.

${ }^{15}$ While statistical power would have been maximized by equalizing the number of treatment and control mandals, the final design had considerably fewer control mandals than treatment mandals since the government wanted to minimize the number of mandals that were deliberately held back from the program. A typical mandal in AP has a population of 50,000 - 75,000 (average $=62,600$ in our study districts) and consists of around 25-30 Gram Panchayats. There are a total of 405 mandals across the 8 districts. We dropped 51 of these mandals (12.6\%) prior to randomizationas they had already begun Smartcard enrollment. An additional mandal in Kurnool district was dropped because no NREGS data were available . Of the remaining mandals, 15 were assigned to treatment and 6 to control in each of Adilabad, Anantapur, Khammam, Kurnool, Nellore; 16 to treatment and 6 to control in Nalgonda; 10 to treatment and 5 to control in Vizianagaram; and 12 to treatment and 4 to control in Kadapa.

${ }^{16}$ Specifically: population, literacy rate, NREGS jobcards, NREGS peak employment rate, and proportion Scheduled Caste, Scheduled Tribe, SSP disability recipient, and other SSP pension recipient.
} 
of participation in most districts (see Figure 1). The intervention was rolled out in treatment mandals shortly after baseline surveys.

We sampled 886 GPs in which to conduct surveys using probability proportional to size (PPS) sampling without replacement, with six GPs per mandal in six districts and four GPs per mandal in the other two, and sampled one habitation ${ }^{17}$ from each GP again by PPS. Within habitations we sampled six households from the frame of all NREGS jobcard holders and four from the frame of all SSP beneficiaries. Our NREGS sample includes five households in which at least one member had worked during May-June according to official records and one household in which no member had worked. This sampling design trades off power in estimating leakage (for which households reported as working matter) against power in estimating rates of access to work (for which all households matter). For our baseline (endline) survey we sampled 8579 (8834) households, of which we were unable to survey or confirm existence of 1005 (300), while 103 (361) households were confirmed as ghost households, leaving us with final sets of 7471 and 8173 households for the baseline and endline surveys respectively. 18

The resulting dataset is a panel at the village level and a repeated cross-section at the household level. This is by design, as the endline sample should be representative of potential participants at that time, but also raises the question whether Smartcards affected the roster of program participants itself. We therefore test for differential attrition by treatment status in the sampling frames for both programs. In control mandals, $2.4 \%$ of jobcards in the baseline frame drop out (likely due to death, migration, or household splits), while $5.9 \%$ of jobcards in the endline frame are new entrants (likely due to the creation of new nuclear families, migration, and new enrollments); neither rate is significantly different in treatment mandals (Table A.3a) 19 There is also no difference in the total number of jobcards across treatment and control mandals (Table A.4). Churn rates are somewhat higher for the SSP (9.7\% dropouts and 16\% entrants) but again balanced across treatment and control (Table A.3b). Finally, new entrants are similar across control and treatment on demographics (household size, caste, religion, education) and socioeconomics (income, consumption, poverty status) for both NREGS and SSP programs. These results suggest that estimated treatment effects do not reflect differential compositional changes in the frame of program

\footnotetext{
${ }^{17}$ A GP is technically comprised of a number of habitations or smaller villages, with an average of 3 habitations per GP.

${ }^{18}$ Note that the high number of surveys (1005) that we are unable to include in our baseline analysis is mainly a result of surveyor error in adhering to extremely rigorous standards used to track sampled households. By endline we had streamlined processes so that almost all 300 households left out were because of genuine inability to trace them. Also, since we have a village-level panel as opposed to a household one, the baseline data is only used to control for village-level means of key outcome variables, and non-completion of individual surveys is less of a concern.

${ }^{19}$ Around $65 \%$ of rural households have jobcards, likely the bulk of those who might participate (authors calculations using National Sample Survey Round 68 (2011-2012)).
} 
participants (Table A.5).

\subsection{Implementation, First-Stage, and Compliance}

We present a brief description of the implementation of the Smartcard project and the extent of actual roll-out for two reasons. First, it helps us distinguish between de jure and de facto realities of the Smartcard program, and thereby helps to better interpret our results by characterizing the program as it was implemented. Second, understanding implementation challenges provides context that may be important if one wishes to extrapolate the likely impacts to a different context.

As may be expected, the implementation of such a complex project faced a number of technical, logistical, and political challenges. Even with the best of intentions and administrative attention, the enrollment of tens of millions of beneficiaries, physical delivery of Smartcards and Point-of-Service devices, identification and training of CSPs, and putting in place cash management protocols would have been a non-trivial task. In addition, local officials (both appointed and elected) who benefited from the status quo system had little incentive to cooperate with the project, and it is not surprising that there were attempts to subvert an initiative to reduce leakage and corruption (as also described in Banerjee et al. (2008)). In many cases, local officials tried to either capture the new system (for instance, by attempting to influence CSP selection), or delay its implementation (for instance, by citing difficulties to beneficiaries in accessing their payments under the new system).

On the other hand, senior officials of GoAP were strongly committed to the project, and devoted considerable administrative resources and attention to successful implementation. More generally, GoAP was strongly committed to NREGS and a leader in utilization of federal funds earmarked for the program. Overall, implementation of the Smartcard Program was a priority for GoAP, but it faced an inevitable set of challenges as described above. Our estimates therefore reflect the impacts of a policy-level decision to implement the Smartcard project at scale, and is net of all the practical complexities of doing so.

Figure 2 plots program rollout in treatment mandals from 2010 to 2012 using administrative data. Clearly, implementation was incomplete. About $80 \%$ of treatment group mandals were "converted" (had at least one converted GP) by the time of the endline in 2012. Conditional on being in a converted mandal, about $80 \%$ (96\%) of GPs had converted for NREGS (SSP) payments, where being "converted" meant that payments were made through the new Bank-TSP-CSP system. These payments could include authenticated payments, unauthenticated payments to workers with Smartcards, and payments to workers without Smartcards 20 The government obtained data only on which payments were

\footnotetext{
${ }^{20}$ Transactions may not be authenticated for a number of reasons, including failure of the authentication device and non-matching of fingerprints.
} 
made to beneficiaries with Smartcards ("carded payments" in their lexicon), which made up about two-thirds of payments within converted GPs by the endline. All told, about $50 \%$ of payments across both programs were "carded" by May 2012 ${ }^{21}$

Turning to compliance with the experimental design, we see that GPs in mandals that were randomly assigned to treatment status were much more likely to have migrated to the new payment system, with 67\% (78\%) of GPs in treated mandals being "carded" for NREGS (SSP) payments, compared to $0.5 \%$ (0\%) of control GPs (Table 1). The overall rate of transactions done with carded beneficiaries was $45 \%$ (59\%) in treatment areas, with basically no carded transactions reported in control areas. We can also assess compliance using data from our survey, which asked pension recipients and NREGS beneficiaries who had worked recently about their Smartcard use. About 38\% (45\%) of NREGS (SSP) beneficiaries in treated mandals said that they used their Smartcards both generally or recently, while between 1-7\% claimed to do so in control mandals. This latter figure likely reflects some beneficiary confusion between enrollment (the process of capturing biometrics and issuing cards) and the onset of carded transactions themselves, as the government did not allow the latter to begin in control areas until after the endline survey. Note that official and survey figures are not directly comparable since the former describe transactions while the latter describe beneficiaries.

Overall, both official and survey records indicate that Smartcards were operational albeit incompletely in treatment areas, with minimal contamination in control areas. We therefore focus on intent-to-treat (ITT) estimates which can be interpreted as the average treatment effects corresponding to an approximately half-complete implementation. ${ }^{22}$ It is important to note, however, that the $50 \%$ rate of Smartcard coverage achieved in two years compares favorably with the performance of arguably simpler changes in payments processes even in high-income countries. The United States, for example, took over fifteen years to convert Social Security transfers to electronic payments 23

\footnotetext{
${ }^{21}$ There was considerable heterogeneity in the extent of Smartcard coverage across the eight study districts, with coverage rates ranging from $31 \%$ in Adilabad to nearly $100 \%$ in Nalgonda district. Heterogeneity across districts does not affect our main estimators as they are conditional on district fixed effects. Tables A.6 and A.7 report correlates of coverage.

${ }^{22}$ While we focus on ITT estimates, we also examine implementation heterogeneity at the village (Table A.6) and individual (Table A.7) level. Villages with a higher fraction of BPL households are significantly more likely to have converted to the new system, and have a higher intensity of coverage. A similar pattern emerges at the individual level for the NREGS, with more vulnerable (lower income, female, scheduled caste) beneficiaries more likely to have Smartcards. No such pattern is seen for SSP households (perhaps because they are all vulnerable to begin with, whereas NREGS is a demand-driven program). Overall, the results are consistent with the idea that banks prioritized enrolling in GPs with more program beneficiaries and hence more potential commission revenue, while conditional on a village being converted the more active welfare participants were more likely to enroll. Our companion study provides a qualitative discussion of implementation heterogeneity (Mukhopadhyay et al., 2013).

${ }^{23}$ Direct deposits started in the mid-1990s; $75 \%$ of payments were direct deposits by January 1999; and check payments finally ceased for good on March 1, 2013. See http://www.ssa.gov/history/1990.html.
} 


\subsection{Estimation}

We report ITT estimates, which compare average outcomes in treatment and control areas. Outcomes are measured at the household level or in some cases (e.g. NREGS work) at the individual level. All regressions are weighted by inverse sampling probabilities to obtain average partial effects for the populations of NREGS jobcard holders or SSP beneficiaries. We include district fixed effects in all regressions, since treatment probability varied across districts, and cluster standard errors at the mandal level. We thus estimate

$$
Y_{i m d}=\alpha+\beta \text { Treated }_{m d}+\delta \text { District }_{d}+\epsilon_{i m d}
$$

where $Y_{i m d}$ is an outcome for household or individual $i$ in mandal $m$ and district $d$, and Treated $_{m}$ is an indicator for whether the mandal was in wave 1 . When possible we also report specifications that include the baseline GP-level mean of the dependent variable, $\bar{Y}_{p m d}^{0}$, to increase precision and to assess sensitivity to any randomization imbalances. We then estimate

$$
Y_{\text {ipmd }}=\alpha+\beta \text { Treated }_{m d}+\gamma \bar{Y}_{p m d}^{0}+\delta \text { District }_{d}+\epsilon_{i p m d}
$$

where $p$ indexes panchayats or GPs. Note that we easily reject $\gamma=1$ in all cases and therefore do not report difference-in-differences estimates. Finally, we test for heterogeneous impacts along GP-level baseline characteristics using a linear interaction specification:

$$
\begin{aligned}
Y_{\text {ipmd }} & =\alpha+\beta_{1} \text { Treated }_{m d}+\beta_{2} \overline{\text { Characteristic }}_{p m d}^{0}+\beta_{3} \overline{\text { Characteristic }}_{p m d}^{0} \cdot \text { Treated }_{m d} \\
& +\delta \text { District }_{d}+\epsilon_{\text {ipmd }}
\end{aligned}
$$

where $\beta_{3}$ is the term of interest, capturing heterogeneity by the given characteristic.

\section{Effects of Smartcard-enabled Payments}

\subsection{Effects on Payment Logistics}

Data from our control group confirm that payments are typically delayed, especially for the NREGS. NREGS recipients in control mandals waited an average of 34 days after finishing a given spell of work to collect payment, more than double the 14 days prescribed by law (Table 2). The collection process is also time-consuming, with the average control recipient spending almost two hours traveling and waiting in line to collect payments.

Smartcards substantially improved this situation. Columns 1 and 2 of Table 2 report that the total time required to collect a payment fell by 21 minutes in mandals assigned to 
treatment (19\% of the control mean). The corresponding estimates for SSP recipients are smaller and not statistically significant, though also negative (Table 2). This is not surprising given that, unlike NREGS payments, SSP payments were made within villages even prior to Smartcards. On the other hand, $85 \%$ of SSP beneficiaries who had received or enrolled for Smartcards reported that Smartcards had sped up payments (Table 6).

NREGS recipients also faced shorter delays in receiving payments after working, and these lags became more predictable. Columns 5 and 6 of Table 2 report that assignment to treatment lowered the mean number of days between working and collecting NREGS payments by 10 days, or $29 \%$ of the control mean (and $50 \%$ of the amount by which this exceeds the statutory limit of 14 days). There is also suggestive evidence that uncertainty about the timing of payments fell. While we do not directly measure beliefs, Columns 7 and 8 show that the variability of payment lags - measured as the absolute deviation from the median mandal level lag, thus corresponding to a robust version of a Levene's test fell by $39 \%$ of the control mean. This reduced variability is potentially valuable for creditconstrained households that need to match the timing of income and expenditure 24

\subsection{Effects on Payment Amounts and Leakage}

Recipients assigned to treatment also received more money. For NREGS recipients, Columns 3 and 4 of Table $3 \mathrm{a}$ show that earnings per household per week during our endline study period increased by Rs. 35, or $24 \%$ of the control group mean. For SSP beneficiaries, earnings per household during the three months preceding our endline survey (May-July) increased by Rs. 18 , or $6.5 \%$ of the control mean.

In contrast, we see no major impacts on fiscal outlays. For the workers sampled into our endline survey; we find no significant difference in official disbursements between treatment and control mandals (columns 1 and 2 of Table 3a 25 Similarly, Columns 1 and 2 of Table $3 \mathrm{~b}$ confirm that SSP disbursements were unaltered.

The fact that recipients report receiving more while government outlays are unchanged implies a reduction in leakage on both programs. Columns 5 and 6 of Table 3 a confirm that the difference between official and survey measures of earnings per worker per week on NREGS fell significantly by Rs. 27. Results on the SSP program mirror the NREGS results: we find a marginally significant reduction in leakage of Rs. 13 per pension per month $(p=0.11)$ (Table 3b).

While we clearly find a significant reduction in NREGS leakage in treatment mandals, estimating the magnitude of this reduction as a fraction of fiscal outlays requires further

\footnotetext{
${ }^{24}$ We did not collect analogous data on date of payment from SSP beneficiaries as payment lags had not surfaced as a major concern for them during initial fieldwork.

${ }^{25}$ The same holds for the full sample of workers in our frame.
} 
assumptions. We find that NREGS households in control mandals report receiving an average of Rs. 20 more per week than the corresponding official outlays, implying a negative rate of leakage - which should technically be impossible. Similarly, we also estimate negative rates of leakage in the SSP control group. Measurement of leakage levels is complicated by the fact that we measure official outlays for the sampled unit (jobcard or pensioner) while measuring amounts received for entire households, which can be larger. In the NREGS case this occurs because many households hold multiple jobcards. While we can (and do) restrict our analysis to the earnings of workers listed on our sampled jobcards, we cannot purge from our data earnings these workers report that were reported to the government on other unsampled jobcards (and hence not included in our official payments estimates) ${ }^{26}$

Given this constraint, our best estimate of average leakage levels adjusts for multiple jobcards by estimating the number of jobcards per household using independent districtlevel data from Round 68 of the National Sample Survey (July 2011-June 2012). Using these data to estimate the number of households with jobcards in each district, and the official jobcard database to determine the number of jobcards in each district, we estimate that the number of jobcards exceeds the number of households with jobcards by an average factor of 1.927 When we then use our district-specific factors to scale up official estimates of work done per household, we estimate an endline leakage rate of $30.8 \%$ in control areas and $20 \%$ in treatment areas $\left(p=0.16\right.$; results in Table A.9). ${ }^{28}$ We also find that treatment assignment has no effect on self-reported ownership of multiple jobcards, so to the extent that this issue interacts with treatment effects on leakage, these interactions are limited. Finally, we also find no evidence of differential changes in numbers or growth rates of jobcards between treatment and control mandals using the full official jobcard frame (Table A.4.

In the SSP case negative estimated levels of leakage are likely to be because we sampled individual pension accounts, but often found multiple pensioners residing within the same household. When we restrict the sample to households with a single pensioner we obtain qualitatively similar treatment effects on receipts and leakage, though with less precision as the sample size is reduced by a third (A.9). Levels of leakage in this restricted sample are

\footnotetext{
${ }^{26}$ The introduction of Smartcards did not reduce the number of jobcards per household. While in theory a de-duplicated Smartcard system should have eliminated multiple jobcards in the same household, in practice the government did not invalidate jobcards that were not linked to Smartcards, because Smartcard enrollment was far from complete. We verify that the total number of jobcards was not different across treatment and control mandals at the time of our endline surveys A.4.

${ }^{27}$ In contrast, when we asked households directly about the number of jobcards they owned we obtained an average response of 1.19 jobcards per household. The gap between this figure and the NSS figure may reflect the fact that some households are not aware that multiple jobcards exist under their name or that they are reluctant to admit holding multiple jobcards. Note that our estimate of jobcards per household is not based on NSS responses on self-reported multiple jobcards. We only use NSS data to estimate the number of households with jobcards, and combine this with administrative data on the total number of jobcards to estimate the average number of jobcards per household.

${ }^{28}$ Note that for these estimates we also include survey reports of all workers within the household.
} 
$8.2 \%$ in control areas and $5.1 \%$ in treatment areas $(p=0.13)$, suggesting a large proportional reduction in leakage of nearly $40 \%$, but from a lower base.

\subsubsection{Robustness of Leakage Results}

One concern about recipients' higher self-reported receipts is that they could reflect in part increased collusion with officials, rather than a pure reduction in leakage. On the NREGS in particular officials might ask workers to report more work than they have actually done to third parties - including government auditors but also our surveyors - and offer to split the proceeds. In this case it is still true that more money reaches the pockets of beneficiaries, but the actual increase may be lower than what we estimate ${ }^{29}$

While directly measuring collusion is clearly infeasible, a number of indirect indicators suggest that it is not driving the reported increase in receipts. First, we can use data from our worksite audits to independently test whether labor supply to NREGS increased in line with the increase in earnings reported by households. While our estimates are imprecise, they suggest an increase in mandals assigned to treatment that is indeed proportional (Table A.10). Second, we asked a subset of survey respondents to indicate whether they had ever been asked to lie about NREGS participation, using the "list method" to elicit means without forcing any individual to reveal their answer, and find no significant difference between the treatment and control groups on this measure ${ }^{30}$ Third, we will see below that beneficiaries overwhelmingly prefer the new payment system to the old, which would be unlikely if officials were capturing all of the gains. Finally, even if these stated preferences are biased, we find strong evidence that Smartcards increased wages in the private sector, consistent with the interpretation that it made NREGS employment a more remunerative alternative, and a more credible outside option for workers (see section 5 ) ${ }^{31}$

\subsubsection{Margins of Leakage Reduction}

We examine leakage reduction along the three margins discussed earlier (ghosts, over-reporting, and under-payment), and find that reduced over-reporting appears to be the main driver of

\footnotetext{
${ }^{29}$ One might also worry that officials collude more with richer beneficiaries, but in our data the poor see receipts increase as much as the rich (section 4.5.

${ }^{30}$ The list method is a standard device for eliciting sensitive information and allows the researcher to estimate population average incidence rates for the sensitive question, though the answers cannot be attributed at the respondent level (Raghavarao and Federer, 1979, Blair and Imai, 2012).

${ }^{31}$ We also find no evidence of Hawthorne effects of the experiment or audits on survey respondents or officials (Table A.11). Our worksite audits were conducted in 5 randomly selected GPs out of the 6 surveyed within each mandal, and we find no difference in survey reports between the audited and unaudited GPs. In addition, we did audits in an additional randomly selected GP that had no survey, and we find no differences in audit outcomes between surveyed and non-surveyed GPs. Finally, using the full official data, we find no effect of either audits or surveys on official data outcomes.
} 
the overall reduction in NREGS leakage. Reductions in NREGS ghost beneficiaries are insignificant (Table 4a, Columns 1 and 2), though the incidence of ghosts is a non-trivial 11\%. This is not surprising given the incomplete coverage of Smartcards, and the government's political decision to not ban unauthenticated payments. Thus, beneficiary lists were not purged of ghosts, and payments to these jobcards are likely to have continued. We also find limited impact on under-payment (Table $4 \mathrm{a}$. Columns 5 and 6). As we find little evidence of under-payment to begin with (control group incidence rate of $2 \%$ ), Smartcards may have limited incremental value on this margin.

However, over-reporting in the NREGS drops substantially, with the proportion of jobcards that had positive official payments reported but zero survey amounts (excluding ghosts who do not even exist) dropping significantly by 8.3 percentage points, or $32 \%$. Figure 3 presents the quantile treatment effect plots on official and survey payments for the study period, and we see (a) no change in official payments, (b) a significant reduction in the incidence of beneficiaries reporting receiving zero payments, and (c) no significant change in amounts received relative to control households who were reporting positive payments. These results suggest that leakage reduction was mainly driven by a reduction in the incidence of "quasi-ghosts" defined as real beneficiaries with jobcards, but who did not previously get any NREGS work or payments (though officials were reporting work on these cards and claiming payments). If some of these households were to have enrolled for a Smartcard, it would no longer be possible for officials to siphon off payments without their knowledge, following which their optimal response appears to have been to provide actual work and payments to these households (see results on access below).

A similar decomposition of the reduction in SSP leakage (Table 4b, Columns 1 and 2), reveals a reduction in all three forms of leakage, suggesting that Smartcard may have improved SSP performance on all dimensions. None of the individual mechanisms see a significant reduction in leakage, which is not surprising given that the overall reduction in SSP leakage is only marginally significant $(p=0.11)$. While individually insignificant, the main mechanism of reduced SSP leakage also appears to be a reduction in over-reporting (similar to the NREGS case), accounting for $70 \%$ of the total reduction in leakage.

A further question for understanding the margins of leakage reduction is the following: If Smartcards reduced officials' rents on NREGS, why did they not increase the total amounts claimed (perhaps by increasing the number of ghosts) to make up for lost rents? Conversations with officials suggest that the main constraint in doing so was the use of budget caps within the NREGS in AP that exogenously fixed the maximum spending on the NREGS for budgeting purposes (also reported by Dutta et al. (2012)). If enforced at the local level, these caps would limit local officials' ability to increase claims in response to Smartcards. While we are not able to directly test for this mechanism, our data are broadly consistent 
with it.

We find that our result finding no significant increase in official payments in treated areas (3a) holds more generally even when we look beyond our study period and sampled GPs. Figure 1 shows the evolution of official disbursements in all GPs in treatment and control mandals, and for every week in 2010 and 2012 (baseline and endline years). The two series track each other closely, with no discernible differences at baseline, endline, or other times in those years. Because of randomization, it is not surprising that the series overlap each other up to and through our baseline study period. What is striking, however, is how closely they continue to track each other after Smartcards began to roll out in the summer of 2010, with no discernible gap emerging. This strongly suggests the existence of constraints that limited local officials' ability to increase the claims of work done ${ }^{32}$

\subsection{Effects on Program Access}

Even if Smartcards reduce leakage, doing so may benefit those who are able to participate, but make it harder for others to participate in the first place. Access could fall for both mechanical and incentive reasons. Mechanically, beneficiaries might be unable to participate if they cannot obtain Smartcards or successfully authenticate. Further, by reducing leakage, Smartcards could reduce officials' primary motive for running programs in the first place. This is particular true for the NREGS which - despite providing a de jure entitlement to employment on demand - is de facto rationed (Dutta et al., 2012). Indeed, in our control group $20 \%$ (42\%) of households reported that someone in their household was unable to obtain NREGS work in May (January) when private sector demand is slack (tight); and only $3.5 \%$ of households said that anyone in their village could get work on NREGS anytime. Thus, the question of whether Smartcards hurt program access is a first order concern.

We find no evidence that this was the case. If anything, households with jobcards in treated mandals were 7.4 percentage points more likely to have done work on the NREGS during our study period, an 18\% increase relative to control (Table 5. Columns 1 and 2). Combined with the results in the previous section showing a significant reduction in the incidence of quasi-ghost NREGS workers, these results suggest that the optimal response of officials to their reduced ability to report work without providing any work or payments to the corresponding worker, was to provide more actual work (this section) and payments (previous section) to these workers. Beyond the increase in actual work during our survey period, columns 3 through 6 show that self-reported access to work also improved at other

\footnotetext{
${ }^{32}$ Note that budgetary allocations are likely to be the binding constraint for NREGS volumes in AP because the state implemented NREGS well and prioritized using all central (federal) fiscal allocations for NREGS. In contrast, states like Bihar had considerable amount of unspent NREGS funds, and ethnographic evidence suggests that the binding constraint in this setting was the lack of local project implementation capacity (Witsoe, 2014).
} 
times of the year. The effects are insignificant in all but one case, but inconsistent with the view that officials "stop trying" once Smartcards are introduced. Bribes paid to access NREGS work were also (statistically insignificantly) lower (Columns 7 and 8).

Given the theoretical concerns about potential negative effects of reducing leakage on program access, how should we interpret the lack of adverse effects in the data? One hypothesis is that officials simply had not had time to adapt their behavior (and reduce their effort on NREGS) by the time we conducted our endline surveys. However, the average converted GP in our data had been converted for 14.5 months at the time of our survey, implying that it had experienced two full peak seasons of NREGS under the new system. More generally, we find no evidence of treatment effects emerging over time in any of the official outcomes which we can observe weekly (e.g. Figure 11). On balance it thus appears more likely that we are observing a steady-state outcome.

A more plausible explanation for our results is that the main NREGS functionary (the Field Assistant) does not manage any other government program, which may limit the opportunities to divert rent-seeking effort to other programs. In other words, despite the reduction in rent-seeking opportunities, implementing NREGS projects may have still been the most lucrative activity for the Field Assistant (note that we still estimate leakage rates of $20 \%$ in the treatment mandals), which may have mitigated potential negative extensive margin effects ${ }^{33}$

We similarly find no evidence of reduced access to the SSP program. Since pensions are valuable and in fixed supply, the main concern here would be that reducing leakage in monthly payments simply displaces this corruption to the registration phase, increasing the likelihood that beneficiaries must pay bribes to begin receiving a pension in the first place. While we do find a significant increase in the net amount pension recipients report collecting per month (Table 3b, Column 4), we find no evidence that this has increased the incidence of bribes at the enrollment stage. Columns 9 and 10 of Table 5 show that the incidence of these bribes among SSP beneficiaries who enrolled after Smartcards implementation began is in fact 5.5 percentage points lower in treated mandals (73\% of the control mean), although this result is not statistically significant. As few pensioners in the control mandals report paying bribes to get registered, the lack of adverse effects on access in treatment mandals, may simply reflect the fact that corruption on this margin was limited to begin with.

\footnotetext{
${ }^{33}$ Of course, the reduction in the present value of the expected flow of rents from holding local office may reduce the attractiveness of these offices and yield an extensive margin effect on the extent to which local elections are contested. We expect to study this in future work for which we are collecting data.
} 


\subsection{Beneficiary Perceptions of the Intervention}

The estimated treatment effects thus far suggest that Smartcards unambiguously improved service delivery. It is possible, however, that our outcome measures miss impacts on some dimension of program performance that deteriorated. We therefore complement our impact estimates with beneficiaries' stated preferences regarding the Smartcard-based payment system as a whole. We asked recipients in converted GPs within treatment mandals who had been exposed to the Smartcard-based payment system to describe the pros and cons of the new process relative to the old and state which they preferred 34

Responses (Table 6) reflect many of our own ex ante concerns, but overall are overwhelmingly positive. Many recipients report concerns about losing their Smartcards (63\% NREGS, $71 \% \mathrm{SSP}$ ) or having problems with the payment reader (60\% NREGS, $67 \% \mathrm{SSP}$ ). Most beneficiaries do not yet trust the Smartcards system enough to deposit money in their accounts. Yet strong majorities (over $80 \%$ in both programs) also agree that Smartcards make payment collection easier, faster, and less manipulable. Overall, 90\% of NREGS beneficiaries and $93 \%$ of SSP beneficiaries prefer Smartcards to the status quo, with only $3 \%$ in either program disagreeing, and the rest neutral.

While stated preferences have well-known limitations, it is worth highlighting their value from a policy point of view. Senior officials in government were much more likely to hear field reports about problems with Smartcards than about positive results. This bias was so severe that GoAP nearly scrapped the entire Smartcards system in 2013, and their decision to not do so was partly in response to reviewing these stated preference data. The episode thus provides an excellent example of the political economy of concentrated costs (to low-level officials who lost rents due to Smartcards, and were vocal with negative feedback) versus diffuse benefits (to millions of beneficiaries, who were less likely to communicate positive feedback) Olson, 1965) 35

\subsection{Effects on Vulnerable Sub-populations}

Even if Smartcards benefited the average program participant, it is possible that it harmed some. For instance, vulnerable households might have a harder time obtaining a Smartcard and end up worse off as a result. While individual-level treatment effects are by definition

\footnotetext{
${ }^{34}$ These questions were asked when beneficiaries had received a Smartcard and used it to pick up wages or had enrolled for, but not received, a physical Smartcard. Out of those who received a Smartcard, $7 \%$ of SSP beneficiaries and $23.4 \%$ of NREGS beneficiaries received a Smartcard but did not use it.

${ }^{35}$ Note also that vested interests trying to subvert the program would typically not do so by admitting that their rents were being threatened, but by making plausible arguments for why the new system would make poor beneficiaries worse off. Our data suggest that some of these concerns are very real (over $60 \%$ of beneficiaries report concerns about losing their Smartcards or encountering a non-functioning card reader), and highlight both the ease with which vested interests can hide behind plausibly genuine concerns, and the value of data from large, representative samples of beneficiaries.
} 
not identifiable, we can test the vulnerability hypothesis in two ways.

First, we examine quantile treatment effects for outcomes that show a significant mean impact (time to collect payment, payment delays, official payments, and payments received as per the survey). We find that the treatment distribution first-order stochastically dominates the control distribution for each of these outcomes (Figure 3). Thus, no treatment household is worse off relative to a control household at the same percentile in the outcome distribution.

Second, we examine whether treatment effects vary as a function of baseline characteristics at the village level ( $\beta_{3}$ in Equation 3.3). We begin with heterogeneity as a function of the baseline value of the outcome variable. The first row of Table 7 suggests broad-based program impacts at all initial values of these outcomes. Overall, the data do not identify any particular group that appears to have suffered on these margins. In the remainder of Table 7 we examine heterogeneity of impact along other measures of vulnerability including affluence (consumption, land ownership and value) and measures of socio-economic disadvantage (fraction of the BPL population and belonging to historically-disadvantaged scheduled castes (SC)), as well as the importance of NREGS to the village (days worked and amounts paid). Again we find no significant heterogeneity of program impact.

\subsection{Mechanisms of Impact}

Because the Smartcards intervention involved both technological changes (biometric authentication) and corresponding organizational changes (payments delivered locally by CSPs working for TSPs), it is natural to examine their relative contributions to the overall effect. Our design does not allow us to do this experimentally. We can, however, compare outcomes within the treatment group to get a suggestive sense. We have variation in our data both in whether CSPs were used for payment (because not all GPs converted) and in whether biometric IDs were used for authentication (because not all beneficiaries in converted GPs received or used biometric IDs).

Table 8 presents a non-experimental decomposition of the total treatment effects along these dimensions. For each of the main outcomes that are significant in the overall ITT estimates, we find significant effects only in the carded GPs, suggesting that the new Smartcardbased payment system was indeed the mechanism for the ITT impacts we find.

In addition, we find that uncarded beneficiaries in carded GPs benefit just as much as carded beneficiaries in these GPs for payment process outcomes such as time to collect payments and reduction in payment lags. While these are non-experimental decompositions, they provide suggestive evidence that converting a village to carded payments may have been the key mechanism by which there were improvements in the process of collecting payments, and also suggest that the implementation protocol followed by GoAP did not inconvenience uncarded beneficiaries in GPs that were converted to the new system. The 
lack of negative impacts for uncarded beneficiaries may be due to GoAPs decision to not insist on carded payments for all beneficiaries (due to the political cost of denying payments to genuine beneficiaries). While permitting uncarded payments may have allowed some amount of leakage to continue even under the new system, it was probably politically prudent to do so in the early stages of the implementation.

However, reductions in leakage appear to be concentrated on households with Smartcards, and we see no evidence of reduced leakage for uncarded beneficiaries (column 10), suggesting that biometric authentication was important for leakage reduction. Note that the lower official and survey payments to uncarded beneficiaries in converted GPs could simply reflect less active workers (who will be paid less) being less likely to have enrolled for the Smartcards, and so our main outcome of interest is leakage.

In short, the data suggest that shifting payments to village-based CSPs drove improvements in the payments process, while biometric authentication drove leakage reductions.

\section{Cost-Effectiveness}

We next estimate the cost-effectiveness of Smartcards as operating at the time of our endline survey. Some of the effects we measure are inherently redistributive, so that any valuation of them depends on the welfare weights we attach to various stakeholders. We therefore quantify costs and efficiency gains before discussing redistribution.

We assume that the cost of the Smartcard system was equal to the $2 \%$ commission that the government paid to banks on payments in converted GPs. This commission was all inclusive, and calibrated to cover all implementation costs of banks and TSPs (including the one-time costs of enrollment and issuing of Smartcards), and is a conservative estimate of the incremental social cost of the Smartcard system because it does not consider the savings accruing to the government from decommissioning the status-quo payment system (e.g. the time of local officials who previously issued payments) ${ }^{36}$ Using administrative data on all NREGS payments in 2012, and scaling down this figure by one-third (since costs were only paid in carded GPs, and only two-thirds of GPs were carded), we calculate the costs of the new payment system at $\$ 4.05$ million in our study districts. The corresponding figure for SSP is $\$ 2.25$ million 37

\footnotetext{
${ }^{36}$ Note that we do not include the time cost of senior officials in overseeing the Smartcard program because they would have had to exercise oversight of the older system as well.

${ }^{37}$ Note that our estimated impacts are ITT effects and are based on converting only two-thirds of GPs. Since Table 8 suggests that the program impacts are driven by GPs that had converted to the new carded system, an alternative approach would be to use the randomization as an instrument to generate IV estimates of the impact of being a carded GP. However, this will simply scale up both the benefit and cost estimates linearly by a factor of 1.5 . We prefer the ITT approach because it does not require satisfying an additional exclusion restriction.
} 
The efficiency gains we observe include reductions in time taken to collect payment, and reductions in the variability of the lag between doing work and getting paid for it. We cannot easily price the latter, though we note that unpredictability is generally thought to be very costly for NREGS workers. To price the former, we estimate the value of time saved conservatively using reported agricultural wages during June, when they are relatively low. Using June wages of Rs. 130/day and assuming a 6.5 hour work-day (estimates of the length of the agricultural work day range from 5 to 8 hours/day), we estimate the value of time at Rs. 20/hour. We assume that recipients collect payments once per spell of work (as they do not keep balances on their Smartcards). Time to collect fell 21 minutes per payment (Table 2), so we estimate the value of time saved at Rs 7 per payment. While modest, this figure applies to a large number of transactions; scaling up by the size of the program in our study districts, we estimate a total saving of $\$ 4.31$ million for NREGS, roughly equal to the government's costs.

Redistributive effects include reduced payment lags (which transfer the value of interest "float" from banks to beneficiaries) and reduced leakage (which transfers funds from corrupt officials to beneficiaries). To quantify the former, we assume conservatively that the value of the float is $5 \%$ per year, the mean interest rate on savings accounts. Multiplied by our estimated 10-day reduction in payment lag and scaled up by the volume of NREGS payments in our study districts, this implies an annual transfer from banks to workers of $\$ 0.40$ million. ${ }^{38}$ To quantify the latter, we multiply the estimated reduction in leakage of $10.8 \%$ by the annual NREGS outlay in our study districts and obtain an estimated annual reduction in leakage of $\$ 32.8$ million.

While valuing these redistributive effects requires subjective judgments about welfare weights, the fact that they both transferred income from the rich to the poor suggests that they should contribute positively to a utilitarian social planner (assuming, for example, a symmetric utilitarian social welfare function with concave individual utility functions). Moreover, if taxpayers or the social planner place a low weight on losses to corrupt officials (as these are "illegitimate" earnings), then the welfare gains from reduced leakage are large.

The estimates above are based on measuring the direct impact of the Smartcards project on the main targeted outcomes of improving the payment process and reducing leakage. In preliminary work we have also found evidence that the intervention led to significant increases in rural private-sector wages, a general equilibrium effect which most likely represents the spillover effects to private labor markets of a better implemented NREGS (Imbert and Papp, forthcoming). Since improving the outside options of rural workers in the lean season was a

\footnotetext{
${ }^{38}$ Note that given the costs of credit-market intermediation workers may well value the use of capital well above the $5 \%$ deposit rate, as is suggested by the $26 \%$ benchmark interest rate for micro-loans, which are the most common form of credit in rural AP. In this case, the value of the reduced payment lag to beneficiaries may exceed the cost to the banks, implying an efficiency gain.
} 
stated objective of the NREGS (Dreze, 2011), these preliminary results further suggest that Smartcards improved the capacity of the government to implement NREGS as intended 39

\section{Conclusion}

While a theoretical literature has emphasized the importance of investing in state capacity for economic development (Besley and Persson, 2009, 2010), the political viability of these investments depends on the magnitude and immediacy of their returns. Advocates argue that improved payments infrastructure may be a high-return investment in state capacity with the potential to significantly improve the implementation of public welfare programs in developing countries. The arguments are appealing, and yet there are many reasons to be skeptical. Implementations of new payments technology must overcome both logistical complexity and the resistance of vested interests. Those that do could potentially backfire by benefiting some while hurting the most vulnerable, or by eroding the incentives of bureaucrats to implement programs they previously viewed as sources of rents. Finally, technologies like biometric authentication could simply cost more than they are worth.

This paper has examined these issues empirically in the context of one of the largest randomized experiments yet conducted: an as-is evaluation of a new payment system built on biometric authentication and electronic benefit transfers introduced into two major social programs in the Indian state of Andhra Pradesh. We find that concerns about barriers to implementation are well-founded, as conversion was limited to $50 \%$ of transactions by the end of the study. Yet the poor gained significantly from the reform: beneficiaries receive payments faster and more reliably, spend less time collecting payments, receive a higher proportion of benefits, and pay less in bribes. These gains do not come at the expense of the most vulnerable beneficiaries, as we see little heterogeneity by baseline characteristics, and treatment distributions stochastically dominate those in control. Nor do they come at the expense of program access, which if anything appears to improve slightly. Nonexperimental decompositions suggest that organizational changes drove improvements in quality of service to beneficiaries, while biometric authentication drove reductions in fraud. Finally, beneficiaries themselves overwhelmingly report preferring the new payment system to the old, and conservative cost-benefit calculations suggest that Smartcards more than justified their costs.

The fact that the theoretically-posited perverse side-effects did not materialize raises the

\footnotetext{
${ }^{39}$ Note that a better implemented NREGS could in principle also have efficiency costs, distorting the allocation of labor to the private sector. A full examination of such effects requires a careful analysis of rural labor markets and the extent of monopsony power exerted by employers, and is beyond the scope of the current paper, which focuses on the impact of Smartcards on the capacity of the government to implement NREGS and SSP programs as intended. We expect to study the GE effects of a better-implemented NREGS on rural labor markets in future work.
} 
question of what the Smartcards initiative did to minimize them. While we cannot provide definitive answers without further experimental variation, our extensive field experience evaluating the project leads us to conjecture that the government's decision to encourage but not mandate Smartcard-based payments may have played an important role. While this left open a major loophole for graft - likely explaining, for example, the lack of impact on ghost beneficiaries - it also ensured that beneficiaries could continue to access their NREGS and SSP benefits even if they were unable to obtain Smartcards or to authenticate. This tradeoff is particularly salient given the recent Supreme Court decision in India prohibiting the government from making possession of a UID mandatory for participation in federal schemes. It also aptly illustrates the more general tradeoff between Type I and Type II errors in the administration of social programs, and suggests that it may be prudent to proceed with UID-linked benefit transfers by making it more attractive to beneficiaries, rather than making it mandatory.

A further conjecture supported by the AP Smartcard experience is that reducing leakage incrementally as opposed to trying to eliminate it rapidly, may mitigate potential negative effects. For instance, the fact that NREGS Field Assistants still found it lucrative to implement projects (albeit with lower rents than before) may explain the lack of adverse effects on the extensive margin of program access. The gradual reduction of leakage may have also reduced the risk of political vested interests subverting the entire program 40

As usual, extrapolating this result to other settings requires care. While the overall level of development in AP almost precisely matches all-India averages, the state is generally perceived as well-administered, and devoted significant resources and senior management time to implementing the Smartcard program well. This raises the possibility that implementation would be more difficult in other settings. On the other hand, the problems that Smartcards were designed to address - slow, unpredictable, and leaky payments - are probably more severe elsewhere, implying greater potential upside. On net it is unclear (to us) whether the social returns would be higher or lower elsewhere. Similarly, forecasting the future evolution of the program requires care. Benefits could deteriorate if interest groups gradually find ways to subvert or capture the Smartcards infrastructure. On the other hand, benefits could increase if and when the government is able to increase coverage and plug remaining loopholes.

More broadly, secure payments infrastructure may also facilitate future increases in the scale and scope of private economic transactions. In the absence of such infrastructure, payments often move through informal networks (Greif, 1993) or not at all. Thus, in addition

\footnotetext{
${ }^{40} \mathrm{~A}$ cautionary tale is provided by the Government of India's pilot project on migrating in-kind subsidies for cooking gas to UID-linked cash transfers of the equivalent subsidy. The pilot stopped benefits to those without UID-linked accounts, which sharply reduced official disbursements of subsidies since many beneficiaries were fake, but triggered strong political opposition following which it was shelved.
} 
to improving the delivery of public programs, investments in secure payments systems can be seen as building public infrastructure - akin to roads, railways, or the internet, which while initially set up by governments for their own use (e.g. moving soldiers to the border quickly or improving intra-government communication) eventually generated substantial benefits for the private sector as well. The gains reported in this paper are based on just two public welfare programs and do not reflect potential future benefits to other public programs or to private sector actors who may benefit from lower transaction costs of making and receiving payments. In this sense our estimates are likely to be a lower bound on the total potential long-term returns of investing in a secure payments infrastructure. 


\section{References}

Acemoglu, Daron, "Theory, General Equilibrium, and Political Economy in Development Economics," Journal of Economic Perspectives, 2010, 24 (3), 17-32.

Aker, Jenny, Rachid Boumnijel, Amanda McClelland, and Niall Tierney, "How do Electronic Transfers Compare? Evidence from a Mobile Money Cash Transfer Experiment in Niger," Technical Report, Tufts University 2013.

Anderson, Siwan, Patrick Francois, and Ashok Kotwal, "Clientilism in Indian Villages," Technical Report, University of British Columbia 2013.

Banerjee, Abhijit, Rachel Glennerster, and Esther Duflo, "Putting a Band-Aid on a Corpse: Incentives for Nurses in the Indian Public Health Care System," Journal of the European Economic Association, 2008, 6 (2-3), 487-500.

Besley, Timothy and Torsten Persson, "The Origins of State Capacity: Property Rights, Taxation, and Politics," American Economic Review, September 2009, 99 (4), 1218-44.

_ and _ , "State Capacity, Conflict, and Development," Econometrica, 012010,78 (1), $1-34$.

Blair, Graeme and Kosuke Imai, "Statistical Analysis of List Experiments," Political Analysis, 2012, 20 (1), 47-77.

Bó, Ernesto Dal, Frederico Finan, and Martín A Rossi, "Strengthening State Capabilities: The Role of Financial Incentives in the Call to Public Service*," The Quarterly Journal of Economics, 2013, 128 (3), 1169-1218.

Bold, Tessa, Mwangi Kimenyi, Germano Mwabu, Alice Ng'ang'a, and Justin Sandefur, "Interventions and Institutions: Experimental Evidence on Scaling up Education Reforms in Kenya," Technical Report, Center for Global Development 2013.

Dahl, Gordon B., Andreas Ravndal Kostol, and Magne Mogstad, "Family Welfare Cultures," NBER Working Paper Series 19237, National Bureau of Economic Research, Inc July 2013.

Dreze, Jean, "Employment Guarantee and the Right to Work," in Reetika Khera, ed., The Battle for Employment Guarantee, Oxford University Press, 2011.

Duflo, Esther, Rema Hanna, and Stephen P. Ryan, "Incentives Work: Getting Teachers to Come to School," American Economic Review, 2012, 102 (4), 1241-78.

Dutta, P., S. Howes, and R. Murgai, "Small but effective: India's targeted unconditional cash transfers," Economic and Political Weekly, 2010, 45 (52), 63-70.

Dutta, Puja, Rinku Murgai, Martin Ravallion, and Dominique van de Walle, "Does India's Employment Guarantee Scheme Guarantee Employment?," Policy Research Working Paper Series 6003, World Bank 2012. 
Fujiwara, Thomas, "Voting Technology, Political Responsiveness, and Infant Health: Evidence from Brazil," Technical Report, Princeton University 2013.

Gelb, Alan and Julia Clark, "Identification for Development: The Biometrics Revolution," Working Paper 315, Center for Global Development 2013.

Gine, Xavier, Jessica Goldberg, and Dean Yang, "Credit Market Consequences of Improved Personal Identification: Field Experimental Evidence from Malawi," American Economic Review, October 2012, 102 (6), 2923-54.

Greif, Avner, "Contract Enforceability and Economic Institutions in Early Trade: The Maghribi Traders' Coalition," American Economic Review, 1993, 83 (3), pp. 525-548.

Harris, Gardiner, "India Aims to Keep Money for Poor Out of Others' Pockets," New York Times, January 52013.

Imbert, Clement and John Papp, "Labor Market Effects of Social Programs: Evidence from India's Employment Guarantee," American Economic Journal: Applied Economics, forthcoming.

Jack, William and Tavneet Suri, "Risk Sharing and Transactions Costs: Evidence from Kenya's Mobile Money Revolution," American Economic Review, 2014, 1, 183-223.

Jayachandran, Seema, "Selling Labor Low: Wage Responses to Productivity Shocks in Developing Countries," Journal of Political Economy, 2006, 114 (3), pp. 538-575.

Khera, Reetika, "The UID Project and Welfare Schemes," Economic and Political Weekly, 2011, $46(9)$.

Kremer, Michael, "The O-Ring Theory of Economic Development," The Quarterly Journal of Economics, 1993, 108 (3), 551-575.

Krusell, Per and Jose-Victor Rios-Rull, "Vested Interests in a Positive Theory of Stagnation and Growth," The Review of Economic Studies, 1996, 63 (2), 301-329.

Leff, Nathaniel, "Economic Development through Bureaucratic Corruption," American Behavioural Scientist, 1964, 8, 8-14.

Lizzeri, Alessandro and Niccola Persico, "The Provision of Public Goods under Alternative Electoral Incentives," American Economic Review, 2001, 91 (1), pp. 223-239.

Mathew, Santhosh and Mick Moore, "State incapacity by design: Understanding the Bihar story," IDS Working Papers, 2011, 2011 (366), 1-31.

Mishra, Neeraj, "A Scam Compounded," India Today, June 202005.

Mukhopadhyay, Piali, Karthik Muralidharan, Paul Niehaus, and Sandip Sukhtankar, "Implementing a Biometric Payment System: The Andhra Pradesh Experience," Technical Report, University of California, San Diego 2013. 
Muralidharan, Karthik, Jishnu Das, Alaka Holla, and Aakash Mohpal, "The Fiscal Cost of Weak Governance: Evidence from Teacher Absence in India," NBER Working Paper Series 20299, National Bureau of Economic Research, Inc 2014.

Niehaus, Paul and Sandip Sukhtankar, "Corruption Dynamics: The Golden Goose Effect," American Economic Journal: Economic Policy, 2013, 5.

_ and _. "The Marginal Rate of Corruption in Public Programs: Evidence from India," Journal of Public Economics, 2013, 104, 52 - 64.

NIPFP, "A Cost-Benefit Analysis of Aadhaar," Technical Report, National Institute for Public Finance and Policy 2012.

Olken, Benjamin A., "Monitoring Corruption: Evidence from a Field Experiment in Indonesia," Journal of Political Economy, April 2007, 115 (2), 200-249.

Olson, Mancur, The Logic of Collective Action: Public Goods and the Theory of Groups, Harvard University Press, 1965.

Pai, Sandeep, "Delayed NREGA payments drive workers to suicide," Hindustan Times, December 292013.

PEO, "Performance Evaluation of Targeted Public Distribution System," Technical Report, Planning Commission, Government of India March 2005.

Prescott, Edward and Stephen Parente, Barriers to Riches, Cambridge: MIT Press, 2000.

Pritchett, Lant, "Is India a Flailing State? Detours on the Four Lane Highway to Modernization," HKS Faculty Research Working Paper Series RWP09-013, Harvard Kennedy School 2010.

Raghavarao, Damaraju and Walter T. Federer, "Block total response as an alternative to the randomized response method in surveys," Journal of the Royal Statistical Society, 1979, $41(1), 40-45$.

Reinikka, Ritva and Jakob Svensson, "Local Capture: Evidence From a Central Government Transfer Program in Uganda," The Quarterly Journal of Economics, May 2004, $119(2), 678-704$.

_ and _ , "Fighting Corruption to Improve Schooling: Evidence from a Newspaper Campaign in Uganda," Journal of the European Economic Association, 04/05 2005, 3 (2-3), 259-267.

Sethi, Chitleen, "70,000 and Still Counting: Fake Old Age Pensioners," Indian Express, April 82014.

Witsoe, Jeffrey, "The Practice of Development: An Ethnographic Examination of the National Rural Employment Guarantee Act in Bihar," Technical Report, Union College 2014.

World Bank, "World Development Report 2004: Making Services Work for Poor People," Technical Report, World Bank 2003. 
Table 1: Official and self-reported use of Smartcards

(a) NREGS

\begin{tabular}{|c|c|c|c|c|}
\hline & \multicolumn{2}{|c|}{ Official data (\%) } & \multicolumn{2}{|c|}{ Survey data (\%) } \\
\hline & $\begin{array}{c}(1) \\
\text { Carded GP }\end{array}$ & $\begin{array}{c}(2) \\
\text { Mean fraction } \\
\text { carded pmts }\end{array}$ & $\begin{array}{c}(3) \\
\text { Pmts generally } \\
\text { carded (village mean) }\end{array}$ & $\begin{array}{c}(4) \\
\text { Most recent pmt } \\
\text { carded (village mean) }\end{array}$ \\
\hline Treatment & $\begin{array}{l}.67^{* * *} \\
(.045)\end{array}$ & $\begin{array}{l}.45^{* * *} \\
(.041)\end{array}$ & $\begin{array}{l}.38^{* * *} \\
(.043)\end{array}$ & $\begin{array}{l}.38^{* * *} \\
(.043)\end{array}$ \\
\hline District FE & Yes & Yes & Yes & Yes \\
\hline $\begin{array}{l}\text { Adj R-squared } \\
\text { Control Mean } \\
\text { N. of cases } \\
\text { Level }\end{array}$ & $\begin{array}{l}.45 \\
.0046 \\
886 \\
\mathrm{GP}\end{array}$ & $\begin{array}{l}.49 \\
.0017 \\
886 \\
\text { GP }\end{array}$ & $\begin{array}{l}.37 \\
.039 \\
824 \\
\text { GP }\end{array}$ & $\begin{array}{l}.36 \\
.013 \\
824 \\
\text { GP }\end{array}$ \\
\hline
\end{tabular}

(b) SSP

\begin{tabular}{|c|c|c|c|c|}
\hline & \multicolumn{2}{|c|}{ Official data (\%) } & \multicolumn{2}{|c|}{ Survey data (\%) } \\
\hline & $\begin{array}{c}(1) \\
\text { Carded GP }\end{array}$ & $\begin{array}{c}(2) \\
\text { Mean fraction } \\
\text { carded pmts }\end{array}$ & $\begin{array}{c}(3) \\
\text { Pmts generally } \\
\text { carded (village mean) }\end{array}$ & $\begin{array}{c}(4) \\
\text { Most recent pmt } \\
\text { carded (village mean) }\end{array}$ \\
\hline Treatment & $\begin{array}{l}.78^{* * *} \\
(.042)\end{array}$ & $\begin{array}{l}.59^{* * *} \\
(.037)\end{array}$ & $\begin{array}{l}.45^{* * *} \\
(.053)\end{array}$ & $\begin{array}{l}.45^{* * *} \\
(.049)\end{array}$ \\
\hline District FE & Yes & Yes & Yes & Yes \\
\hline Adj R-squared & .55 & .54 & .39 & .39 \\
\hline Control Mean & 0 & 0 & .069 & . 044 \\
\hline N. of cases & 886 & 886 & 884 & 884 \\
\hline Level & GP & GP & GP & GP \\
\hline
\end{tabular}

This table analyzes usage of Smartcards for NREGS and SSP payments as of July 2012. Each observation is a gram panchayat ("GP": administrative village). "Carded GP" is a gram panchayat that has moved to Smartcard-based payment, which happens once $40 \%$ of beneficiaries have been issued a card. "Mean fraction carded pmts" is the proportion of transactions done with carded beneficiaries in carded GPs. Both these outcomes are from official data. Columns 3 and 4 report surveybased measures of average beneficiary use of Smartcards or a biometric-based payment system in the GP. Standard errors clustered at mandal level in parentheses. Statistical significance is denoted as: ${ }^{*} p<0.10,{ }^{* *} p<0.05,{ }^{* * *} p<0.01$ 
Table 2: Access to payments

\begin{tabular}{|c|c|c|c|c|c|c|c|c|}
\hline & \multicolumn{4}{|c|}{ Time to Collect (Min) } & \multicolumn{4}{|c|}{ Pmt Lag (Days) } \\
\hline & (1) & (2) & (3) & (4) & $\begin{array}{c}(5) \\
\text { Average }\end{array}$ & $\begin{array}{c}(6) \\
\text { Average }\end{array}$ & $\begin{array}{c}(7) \\
\text { Deviation }\end{array}$ & $\begin{array}{c}(8) \\
\text { Deviation }\end{array}$ \\
\hline Treatment & $\begin{array}{l}-21^{* *} \\
(9.3)\end{array}$ & $\begin{array}{l}-21^{* *} \\
(8.7)\end{array}$ & $\begin{array}{l}-5.6 \\
(5.3)\end{array}$ & $\begin{array}{l}-2.8 \\
(5.6)\end{array}$ & $\begin{array}{l}-7.1^{*} \\
(3.8)\end{array}$ & $\begin{array}{c}-10^{* * *} \\
(3.6)\end{array}$ & $\begin{array}{c}-2.9^{* * *} \\
(1.1)\end{array}$ & $\begin{array}{c}-4.7^{* * *} \\
(1.5)\end{array}$ \\
\hline \multicolumn{9}{|l|}{ Carded GP } \\
\hline BL GP Mean & & $\begin{array}{l}.08^{*} \\
(.041)\end{array}$ & & $\begin{array}{l}.22^{* * *} \\
(.069)\end{array}$ & & $\begin{array}{l}-.027 \\
(.09)\end{array}$ & & $\begin{array}{l}.043 \\
(.054)\end{array}$ \\
\hline District FE & Yes & Yes & Yes & Yes & Yes & Yes & Yes & Yes \\
\hline Week Fe & No & No & No & No & Yes & Yes & Yes & Yes \\
\hline Adj R-squared & .06 & .08 & .06 & .11 & .14 & .31 & .07 & .17 \\
\hline Control Mean & 112 & 112 & 77 & 77 & 34 & 34 & 12 & 12 \\
\hline N. of cases & 10252 & 10181 & 3814 & 3591 & 14279 & 7254 & 14279 & 7254 \\
\hline Level & Indiv. & Indiv. & Indiv. & Indiv. & Indiv-Week & Indiv-Week & Indiv-Week & Indiv-Week \\
\hline Survey & NREGS & NREGS & SSP & SSP & NREGS & NREGS & NREGS & NREGS \\
\hline
\end{tabular}

The dependent variable in columns 1-4 is the average time taken to collect a payment (in minutes), including the time spent on unsuccessful trips to payment sites, with observations at the beneficiary level. The dependent variable in columns 5-6 is the average lag (in days) between work done and payment received on NREGS, while columns 7-8 report results for absolute deviations from the median mandal lag. Standard errors clustered at mandal level in parentheses. Statistical significance is denoted as: ${ }^{*} p<0.10,{ }^{* *} p<0.05,{ }^{* * *} p<0.01$ 
Table 3: Official and survey reports of program benefits

(a) NREGS

\begin{tabular}{lcccccccc}
\hline & \multicolumn{2}{c}{ Official } & & \multicolumn{2}{c}{ Survey } & & \multicolumn{2}{c}{ Leakage } \\
\cline { 2 - 3 } & $(1)$ & $(2)$ & & $(3)$ & $(4)$ & & $(5)$ & $(6)$ \\
\hline Treatment & 9.9 & 7.6 & & $35^{* *}$ & $35^{* *}$ & & $-25^{*}$ & $-27^{* *}$ \\
& $(12)$ & $(12)$ & & $(15)$ & $(15)$ & & $(13)$ & $(13)$ \\
BL GP Mean & & $.12^{* * *}$ & & $.11^{* * *}$ & & $.089^{* *}$ \\
& & $(.027)$ & & $(.037)$ & & $(.038)$ \\
District FE & Yes & Yes & Yes & Yes & & Yes & Yes \\
\hline Adj R-squared & .03 & .05 & .05 & .06 & & .03 & .04 \\
Control Mean & 127 & 127 & & 146 & 146 & & -20 & -20 \\
N. of cases & 5179 & 5143 & 5179 & 5143 & & 5179 & 5143 \\
\hline
\end{tabular}

(b) SSP

\begin{tabular}{lcccccccc}
\hline & \multicolumn{2}{c}{ Official } & & \multicolumn{2}{c}{ Survey } & & \multicolumn{2}{c}{ Leakage } \\
\cline { 2 - 3 } & $(1)$ & $(2)$ & & $(3)$ & $(4)$ & & $(5)$ & $(6)$ \\
\hline Treatment & 4.4 & 5 & & 13 & $18^{*}$ & & -8.5 & -13 \\
& $(5.5)$ & $(5.6)$ & & $(10)$ & $(10)$ & & $(8.3)$ & $(8.2)$ \\
BL GP Mean & & $.16^{*}$ & & $.082^{* * *}$ & & .045 \\
& & $(.093)$ & & $(.03)$ & & $(.032)$ \\
District FE & Yes & Yes & & Yes & Yes & & Yes & Yes \\
\hline Adj R-squared & .00 & .01 & .01 & .01 & & .01 & .01 \\
Control Mean & 250 & 250 & 292 & 292 & & -41 & -41 \\
N. of cases & 3360 & 3157 & 3360 & 3157 & & 3360 & 3157 \\
\hline
\end{tabular}

The regressions in both panels include all sampled households who were a) found by survey team to match official record or b) listed in official records but confirmed as "ghost" households. "Ghost households" refer to households (or all beneficiaries within households) that were confirmed not to exist, or who had permanently migrated before the study period started on May 28, 2012 (May 31, 2010 for baseline). In panel (a), each observation refers to household-level average weekly amounts for NREGS work done during the study period (baseline in 2010 - May 31 to July 4; endline in 2012 - May 28 to July 15). "Official" refers to amounts paid as listed in official muster records. "Survey" refers to payments received as reported by beneficiaries. "Leakage" is the difference between these two amounts. In panel (b), each observation refers to the average SSP monthly amount for the period May, June, and July. "Official" refers to amounts paid as listed in official disbursement records. "Survey" refers to payments received as reported by beneficiaries. "Leakage" is the difference between these two amounts. Standard errors clustered at mandal level in parentheses. Statistical significance is denoted as: ${ }^{*} p<0.10,{ }^{* *} p<0.05$, ${ }^{* * *} p<0.01$ 
Table 4: Illustrating mechanisms of leakage reduction

(a) NREGS

\begin{tabular}{|c|c|c|c|c|c|c|}
\hline & \multicolumn{2}{|c|}{ Ghost households (\%) } & \multicolumn{2}{|c|}{ Other overreporting (\%) } & \multicolumn{2}{|c|}{ Bribe to collect $(\%)$} \\
\hline & (1) & $(2)$ & (3) & $(4)$ & $(5)$ & (6) \\
\hline Treatment & $\begin{array}{c}-1.1 \\
(2)\end{array}$ & $\begin{array}{l}-1.1 \\
(2)\end{array}$ & $\begin{array}{c}-8.2^{* *} \\
(3.3)\end{array}$ & $\begin{array}{c}-8.3^{* *} \\
(3.6)\end{array}$ & $\begin{array}{c}-.21 \\
(.0088)\end{array}$ & $\begin{array}{l}-.28 \\
(.92)\end{array}$ \\
\hline BL GP Mean & & $\begin{array}{l}-1.3 \\
(6.7)\end{array}$ & & $\begin{array}{c}1.9 \\
(4.3)\end{array}$ & & $\begin{array}{c}1.4 \\
(.018)\end{array}$ \\
\hline District FE & Yes & Yes & Yes & Yes & Yes & Yes \\
\hline Adj R-squared & .02 & .02 & .05 & .04 & .01 & .01 \\
\hline Control Mean & .11 & .11 & .26 & .26 & .021 & .021 \\
\hline N. of cases & 5314 & 5278 & 3984 & 3703 & 10437 & 10366 \\
\hline Level & HHD & HHD & HHD & HHD & Indiv. & Indiv. \\
\hline
\end{tabular}

(b) SSP

\begin{tabular}{|c|c|c|c|c|c|c|}
\hline & \multicolumn{2}{|c|}{ Ghosts (Rs) } & \multicolumn{2}{|c|}{ Other Overreporting ( $\mathrm{Rs}$ ) } & \multicolumn{2}{|c|}{ Underpayment (Rs) } \\
\hline & (1) & $(2)$ & (3) & (4) & (5) & (6) \\
\hline Treatment & $\begin{array}{l}-2.7 \\
(2.6)\end{array}$ & $\begin{array}{l}-2.2 \\
(2.6)\end{array}$ & $\begin{array}{l}-3.6 \\
(8.1)\end{array}$ & $\begin{array}{l}-9.1 \\
(7.7)\end{array}$ & $\begin{array}{l}-2.2 \\
(1.8)\end{array}$ & $\begin{array}{l}-2.3 \\
(1.9)\end{array}$ \\
\hline BL GP Mean & & $\begin{array}{c}.19 \\
(.16)\end{array}$ & & $\begin{array}{l}.092^{* * *} \\
(.023)\end{array}$ & & $\begin{array}{l}-.017 \\
(.044)\end{array}$ \\
\hline District FE & Yes & Yes & Yes & Yes & Yes & Yes \\
\hline Adj R-squared & .01 & .01 & .00 & .01 & .01 & .01 \\
\hline Control Mean & 11 & 11 & -54 & -54 & 2.4 & 2.4 \\
\hline N. of cases & 3360 & 3157 & 3360 & 3157 & 3360 & 3157 \\
\hline
\end{tabular}

This table analyzes channels of reduction in leakage. Panel (a) reports the incidence of the three channels - ghosts, overreporting, and underpayment - for NREGS, while panel (b) decomposes actual amounts (in Rupees) into these channels in the case of SSP. In both tables, "Ghost households" refer to households (or all beneficiaries within households) that were confirmed not to exist, or who had permanently migrated before the study period started on May 28, 2012 (May 31, 2010 for baseline). "Other overreporting (\%)" for NREGS is the incidence of jobcards that had positive official payments reported but zero survey amounts (not including ghosts). "Bribe to collect" refers to bribes paid in order to receive payments on NREGS. "Other overreporting" for SSP is the difference between what officials report beneficiaries as receiving and what beneficiaries believe they are entitled to. "Underpayment" for SSP is the monthly amount paid in order to receive their pensions in May-July 2012. Standard errors clustered at mandal level in parentheses. Statistical significance is denoted as: ${ }^{*} p<0.10,{ }^{* *} p<0.05,{ }^{* * *} p<0.01$ 


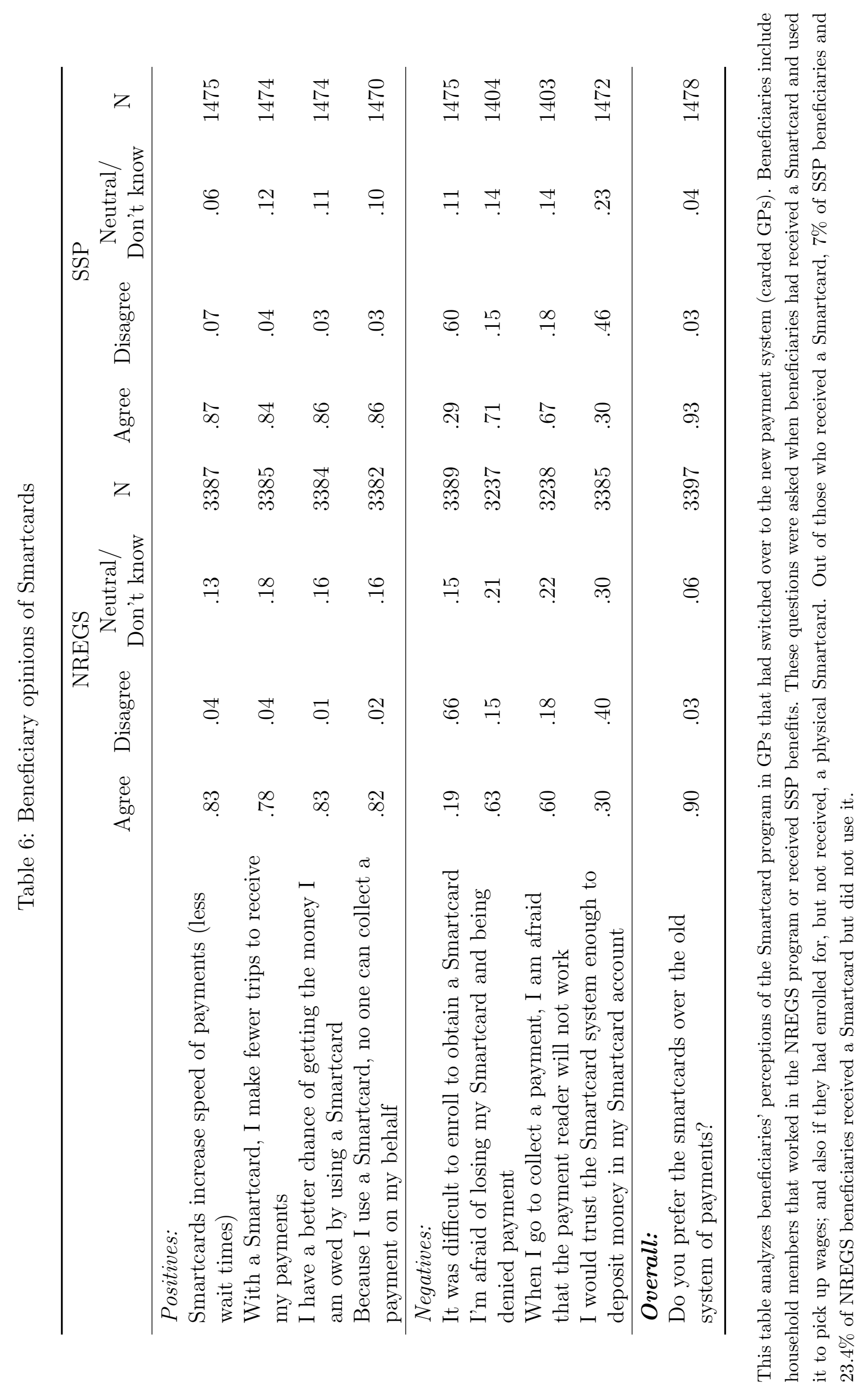


Table 7: Heterogeneity by baseline characteristics

(a) NREGS

\begin{tabular}{|c|c|c|c|c|}
\hline & Time to Collect & Payment Lag & Official Payments & Survey Payments \\
\hline & $(1)$ & $(2)$ & $(3)$ & $(4)$ \\
\hline BL GP Mean & $\begin{array}{l}.024 \\
(.08)\end{array}$ & $\begin{array}{c}.16 \\
(.25)\end{array}$ & $\begin{array}{l}.0049 \\
(.042)\end{array}$ & $\begin{array}{c}.047 \\
(.074)\end{array}$ \\
\hline Consumption (Rs. 1,000) & $\begin{array}{r}-.087 \\
(.16)\end{array}$ & $\begin{array}{c}-.01 \\
(.027)\end{array}$ & $\begin{array}{c}-.017 \\
(.2)\end{array}$ & $\begin{array}{c}-.044 \\
(.26)\end{array}$ \\
\hline GP Disbursement, NREGS (Rs. 1,000) & $\begin{array}{l}.015^{* *} \\
(.0073)\end{array}$ & $\begin{array}{r}-.00027 \\
(.0013)\end{array}$ & $\begin{array}{c}.012 \\
(.0093)\end{array}$ & $\begin{array}{l}.0065 \\
(.016)\end{array}$ \\
\hline SC Proportion & $\begin{array}{c}.61 \\
(48)\end{array}$ & $\begin{array}{c}22 \\
(14)\end{array}$ & $\begin{array}{c}3.5 \\
(49)\end{array}$ & $\begin{array}{c}13 \\
(51)\end{array}$ \\
\hline BPL Proportion & $\begin{array}{c}-65 \\
(130)\end{array}$ & $\begin{array}{l}-29 \\
(24)\end{array}$ & $\begin{array}{c}-72 \\
(113)\end{array}$ & $\begin{array}{l}-164 \\
(112)\end{array}$ \\
\hline District FE & Yes & Yes & Yes & Yes \\
\hline Week FE & No & Yes & No & No \\
\hline $\begin{array}{l}\text { Control Mean } \\
\text { Level } \\
\text { N. of cases }\end{array}$ & $\begin{array}{c}112 \\
\text { Indiv. } \\
10204\end{array}$ & $\begin{array}{c}34 \\
\text { Indiv-Week } \\
12390\end{array}$ & $\begin{array}{c}127 \\
\text { HHD } \\
5030\end{array}$ & $\begin{array}{c}146 \\
\text { HHD } \\
5030\end{array}$ \\
\hline
\end{tabular}

(b) SSP

\begin{tabular}{|c|c|c|c|}
\hline & Time to Collect & Official Payments & Survey Payments \\
\hline & (1) & (2) & (3) \\
\hline BL GP Mean & $\begin{array}{l}.22^{* *} \\
(.1)\end{array}$ & $\begin{array}{l}-.015 \\
(.086)\end{array}$ & $\begin{array}{c}.029 \\
(.094)\end{array}$ \\
\hline Consumption (Rs. 1,000) & $\begin{array}{c}-.25^{* *} \\
(.11)\end{array}$ & $\begin{array}{l}-.012 \\
(.099)\end{array}$ & $\begin{array}{r}-.099 \\
(.23)\end{array}$ \\
\hline GP Disbursement, SSP (Rs. 1000) & $\begin{array}{l}-.089 \\
(.095)\end{array}$ & $\begin{array}{c}.056 \\
(.074)\end{array}$ & $\begin{array}{c}.11 \\
(.12)\end{array}$ \\
\hline SC Proportion & $\begin{array}{c}18 \\
(17)\end{array}$ & $\begin{array}{l}-29 \\
(23)\end{array}$ & $\begin{array}{l}-24 \\
(37)\end{array}$ \\
\hline BPL Proportion & $\begin{array}{l}-64^{*} \\
(35)\end{array}$ & $\begin{array}{c}128^{* *} \\
(53)\end{array}$ & $\begin{array}{l}100 \\
(84)\end{array}$ \\
\hline District FE & Yes & Yes & Yes \\
\hline Control Mean & 77 & 257 & 298 \\
\hline Level & Indiv. & Indiv. & Indiv. \\
\hline N. of cases & 3590 & 2997 & 2997 \\
\hline
\end{tabular}

This table shows heterogeneous effects on major endline outcomes from GP-level baseline characteristics. Each cell shows the coefficient on the baseline characteristic interacted with the treatment indicator in separate regressions. "BL GP Mean" is the baseline GP-level mean for the outcome variable. "Consumption (Rs. 1,000)" is annualized consumption. "GP Disbursement (Rs. 1000)" is total NREGS/SSP payment amounts for the period Jan 1, 2010 to July 22, 2010. "SC Proportion" is the proportion of NREGS workspells performed by schedule caste workers/SSP beneficiaries in the period from Jan 1, 2010 to July 22, 2010. "BPL Proportion" is the proportion of households with a BPL card in the baseline survey. Standard errors are clustered at the mandal level. Statistical significance is denoted as: ${ }^{*} p<0.10,{ }^{* *} p<0.05,{ }^{* * *} p<0.01$ 


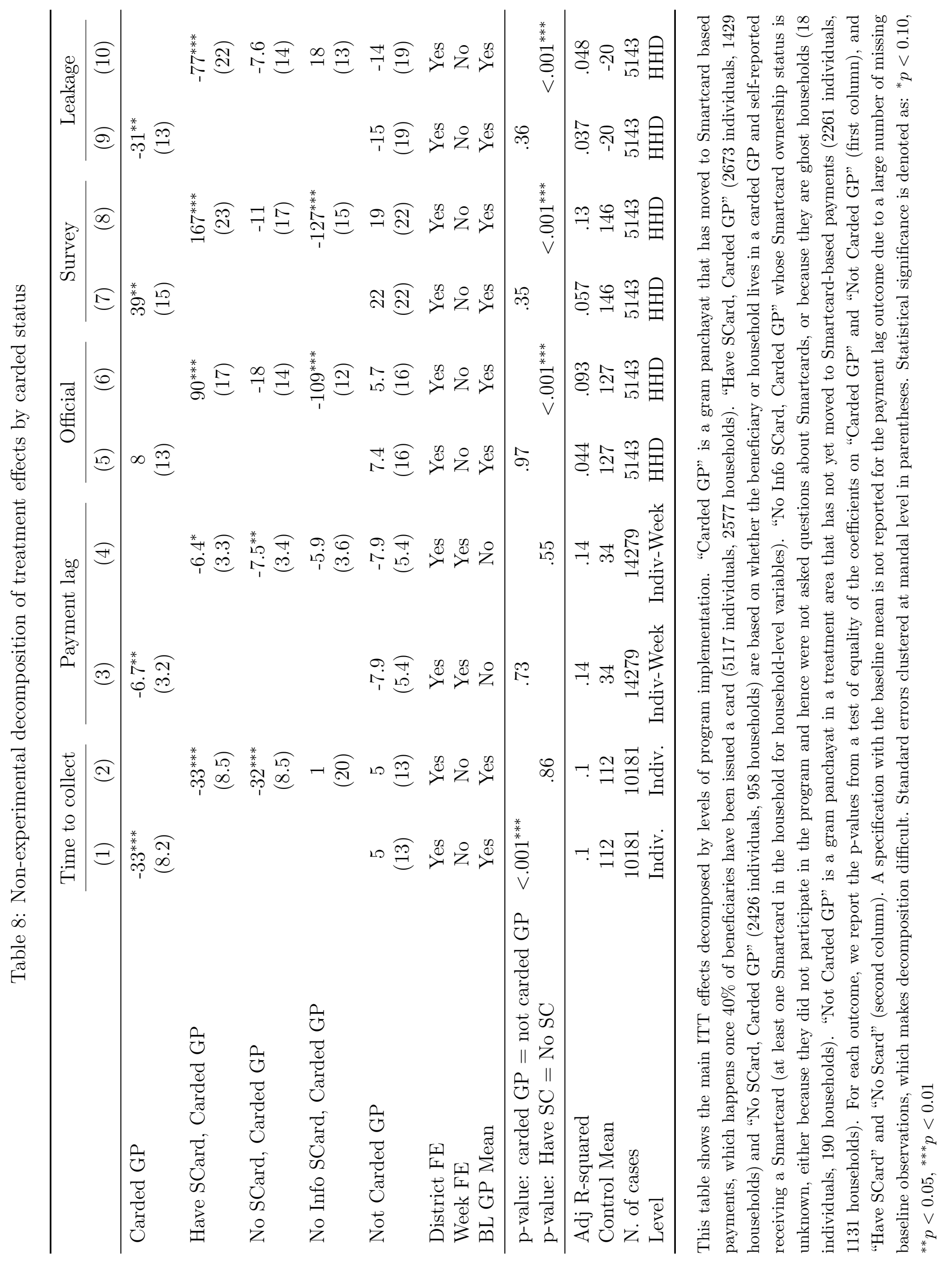




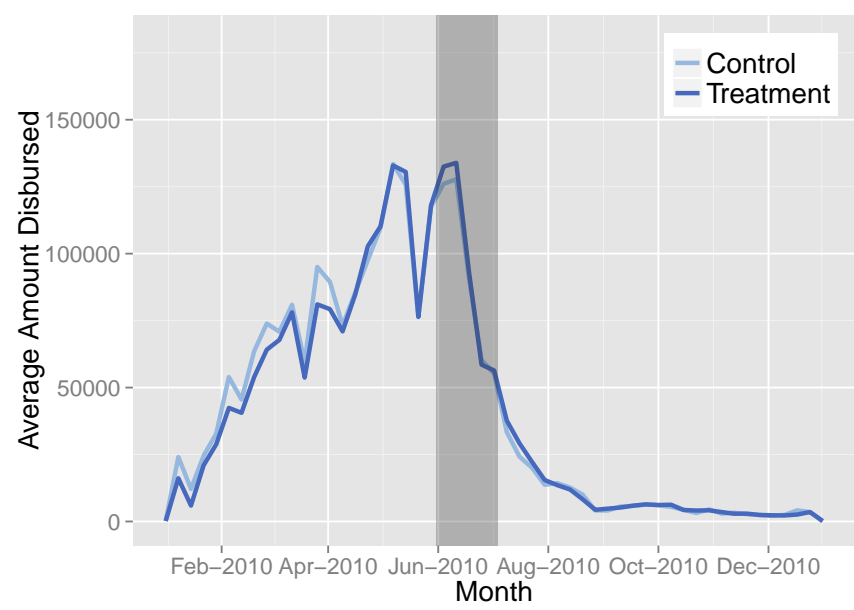

(a) 2010

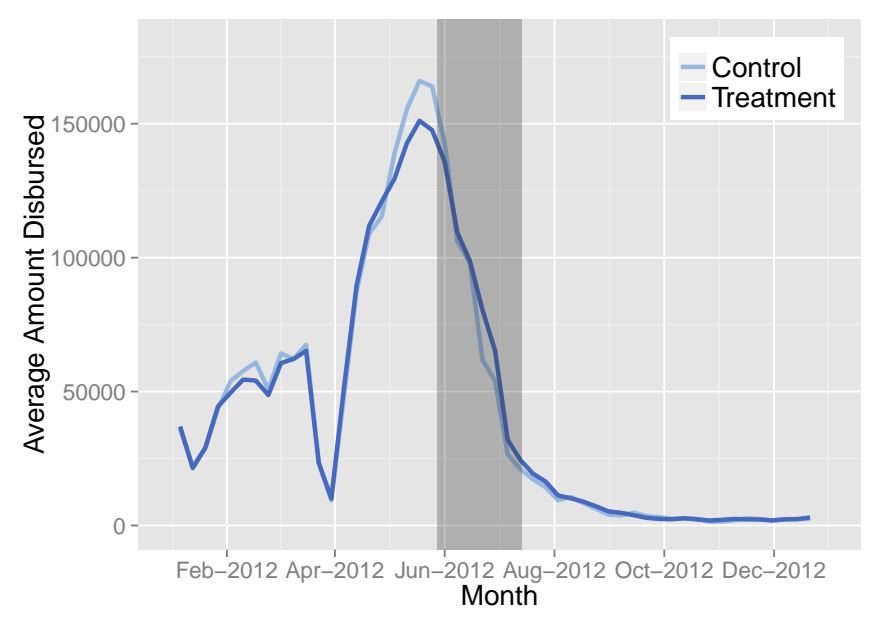

(b) 2012

Figure 1: Official disbursement trends in NREGS

This figure shows official NREGS payments for all workers averaged at the GP-week level for treatment and control areas. The grey shaded bands denote the study periods on which our survey questions focus (baseline in 2010 - May 31 to July 4; endline in 2012 - May 28 to July 15).

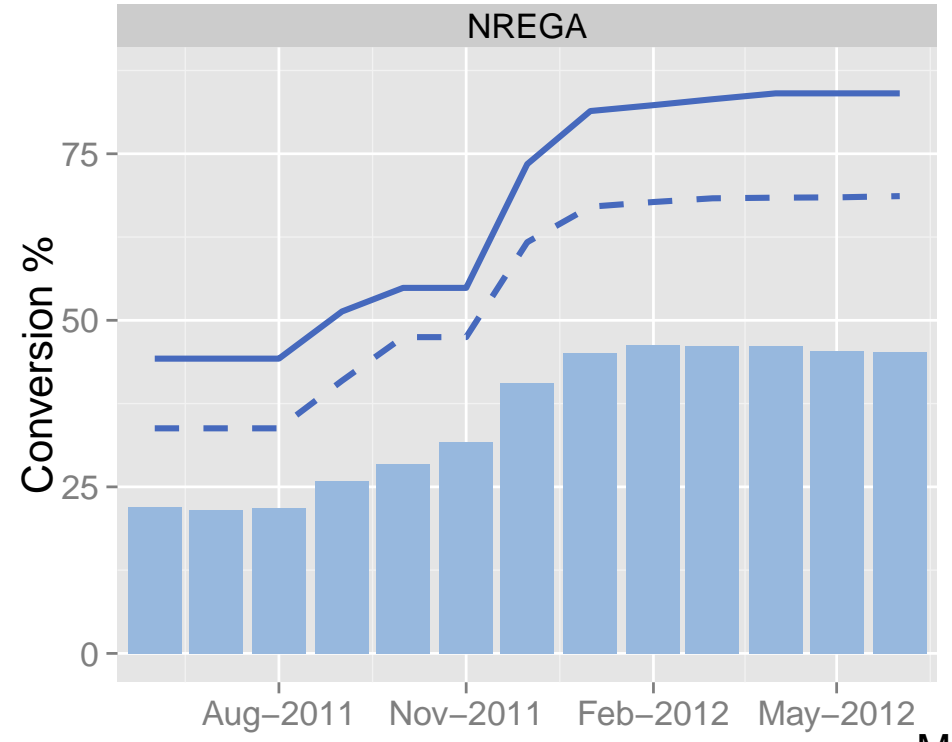

Month

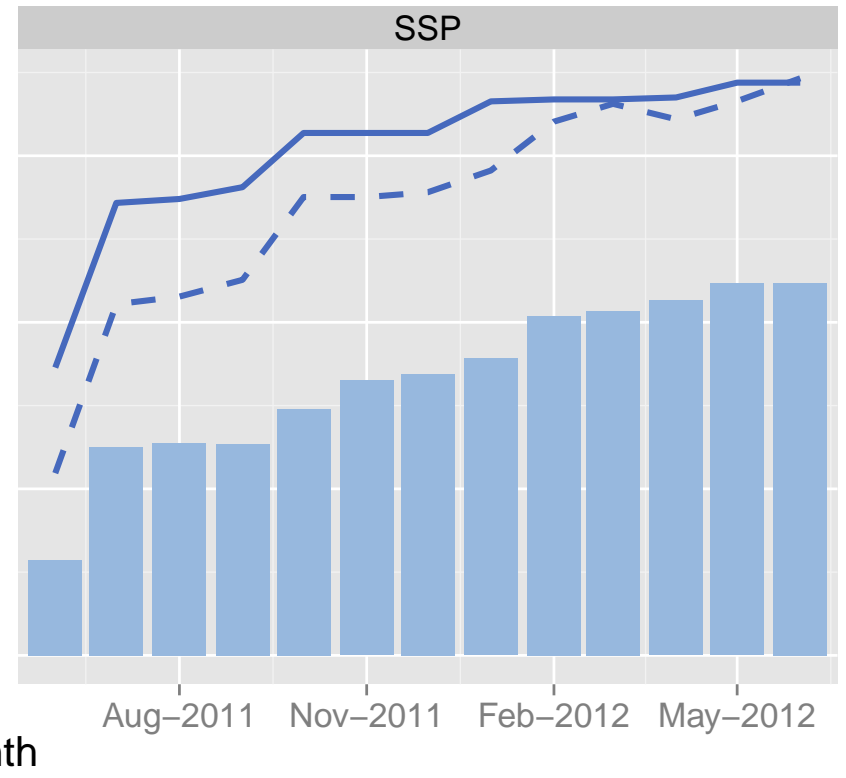

$\%$ Carded Payments

Figure 2: Rollout of Smartcard integration with welfare programs

This figure shows program rollout in aggregate and at different conversion levels. A GP converts to the Smartcard-enabled system based on beneficiary enrollment in the program. "\% Mandals" is the percentage of mandals converted in a district. A mandal converts when at least one GP in the mandal converts. "\% GPs" is the percentage of converted GPs across all districts. "\% Carded Payments" is obtained by multiplying \% Mandals by \% GPs in converted mandals and \% payments to carded beneficiaries in converted GPs. 


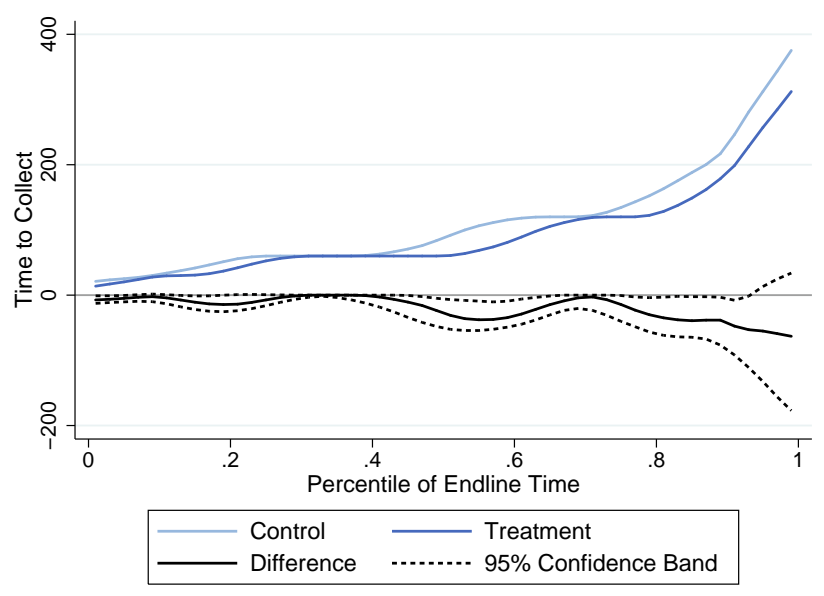

(a) Time to collect - NREGS

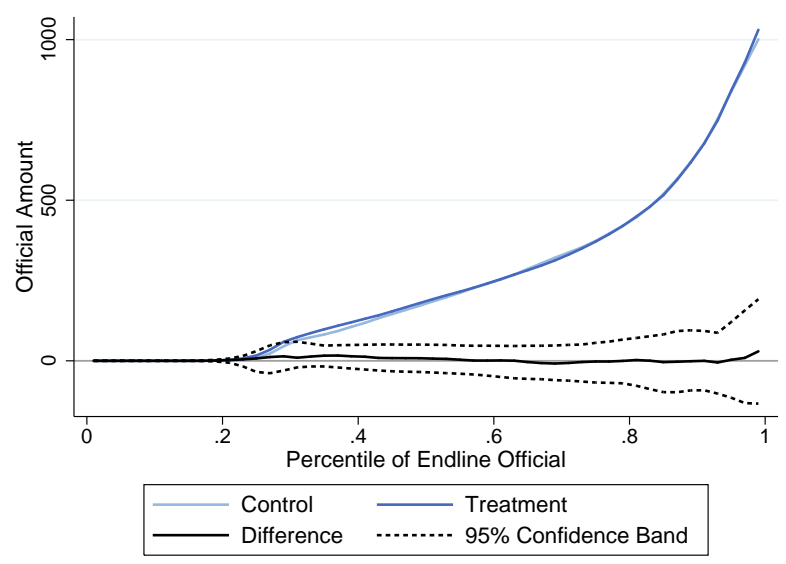

(c) Official - NREGS

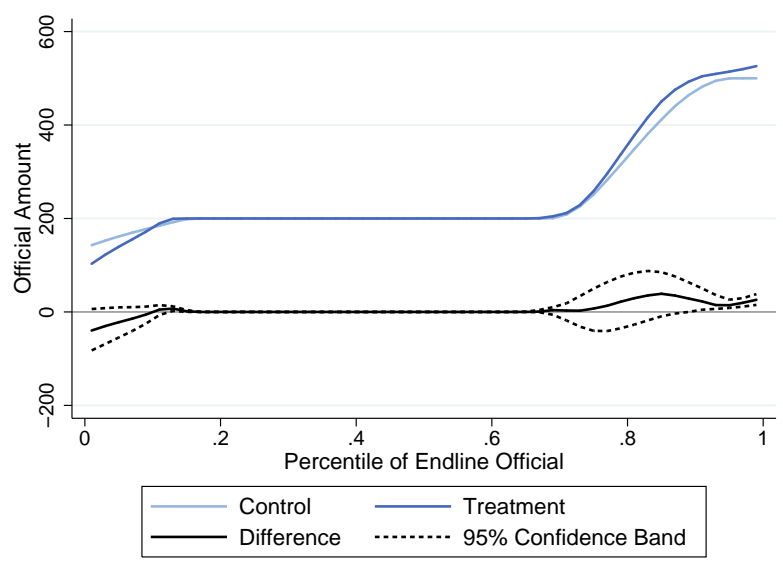

(e) Official - SSP

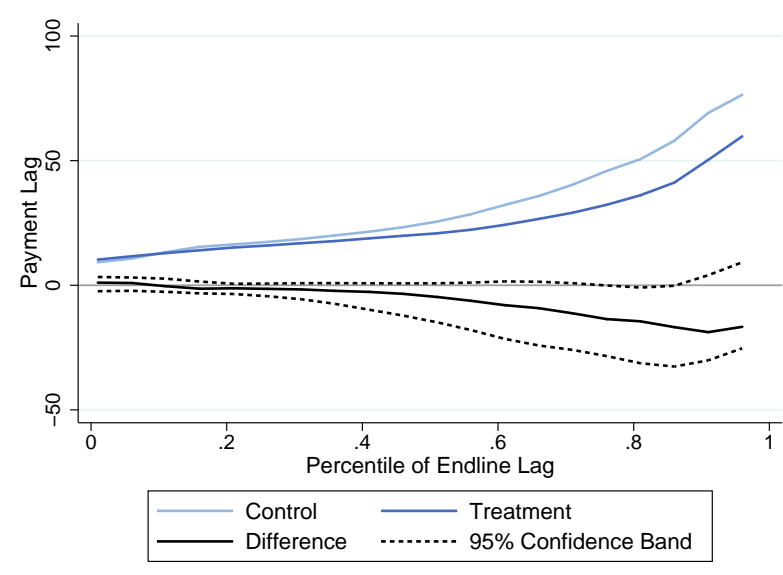

(b) Payment Lag - NREGS

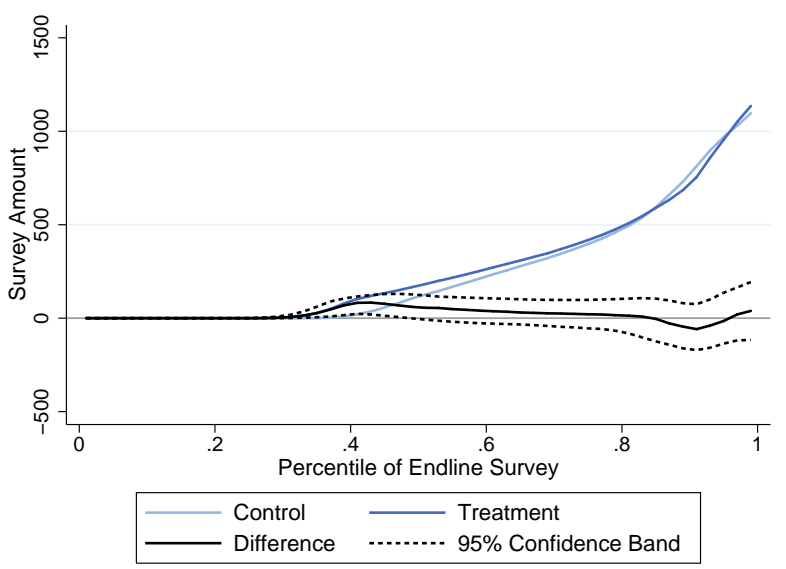

(d) Survey - NREGS

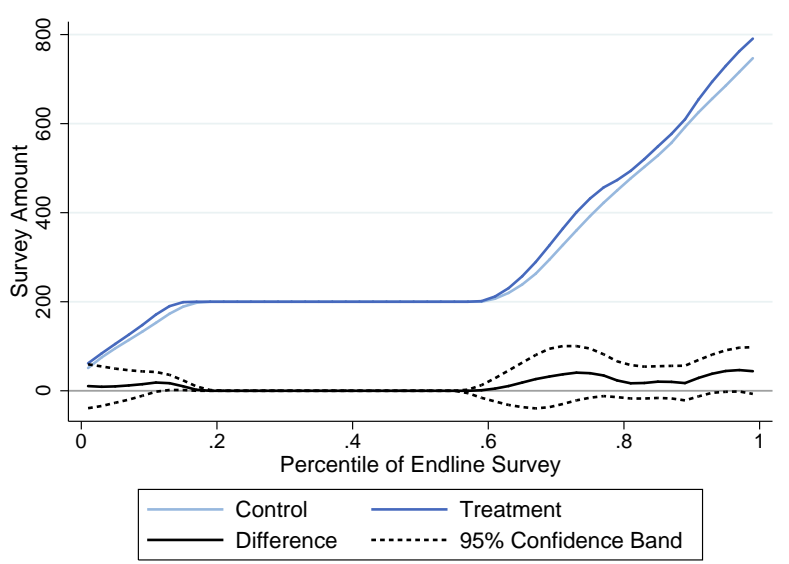

(f) Survey - SSP

Figure 3: Quantile Treatment Effects on Key Outcomes

Panels (a)-(f) show nonparametric treatment effects. "Time to collect - NREGS" is the average time taken to collect a payment, including the time spent on unsuccessful trips to payment sites. "Payment Lag - NREGS" is the average lag (in days) between work done and payment received under NREGS. The official payment amounts, "Official - NREGS" and "Official - SSP", refer to payment amounts paid as listed in official muster/disbursement records. The survey payment amounts, "survey - NREGS" and "survey - SSP" refers to payments received as reported by beneficiaries. The NREGS data is taken from the study period (endline was 2012 - May 28 to July 15). The SSP official amount, "official - SSP," is an average of June, July and August disbursements to the beneficiary. The SSP survey reported amount, "survey - SSP," is the amount beneficiaries report they are supposed to receive minus the amount they need to pay to collect the pension. All lines are fit by a kernel-weighted local polynomial smoothing function with Epanechnikov kernel and probability weights, with standard errors bootstrapped. 
Table A.1: Balance on baseline characteristics: Official records

\begin{tabular}{lcccc}
\hline & Treatment & Control & Difference & p-value \\
\hline Population & 43734 & 43578 & 155 & .94 \\
Pensions per capita & .12 & .12 & .0013 & .79 \\
Jobcards per capita & .55 & .55 & -.0063 & .84 \\
Literacy rate & .45 & .45 & .0039 & .74 \\
\% SC & .19 & .19 & .003 & .81 \\
\% ST & .1 & .12 & -.016 & .53 \\
\% population working & .53 & .52 & .0047 & .63 \\
\% male & .51 & .51 & .00018 & .88 \\
\% old age pensions & .48 & .49 & -.0095 & .83 \\
\% weaver pensions & .009 & .011 & -.0015 & .71 \\
\% disabled pensions & .1 & .1 & .0021 & .83 \\
\% widow pensions & .21 & .2 & .014 & .48 \\
\hline
\end{tabular}

This table presents outcome means from official data on mandal characteristics. Column 3 reports the difference in treatment and control means, while column 4 reports the p-value on the treatment indicator, both from simple regressions of the outcome with district fixed effects as the only controls. A "jobcard" is a household level official enrollment document for the NREGS program. "SC" ("ST") refers to Scheduled Castes (Tribes), historically discriminated-against sections of the population now accorded special status and affirmative action benefits under the Constitution. Standard errors are clustered at the mandal level. Statistical significance is denoted as: ${ }^{*} p<0.10,{ }^{* *} p<0.05,{ }^{* * *} p<0.01$ 
Table A.2: Balance on baseline characteristics: Household survey

\begin{tabular}{lcccccccc}
\hline & \multicolumn{4}{c}{ NREGS } & \multicolumn{4}{c}{ SSP } \\
& Treatment & Control & Difference & p-value & Treatment & Control & Difference & p-value \\
\hline HHD members & 4.8 & 4.8 & .02 & .9 & 4.1 & 4.2 & -.15 & .4 \\
BPL & .98 & .98 & .0042 & .73 & .98 & .97 & .0039 & .65 \\
Scheduled caste & .22 & .25 & -.027 & .34 & .19 & .23 & $-.036^{*}$ & .092 \\
Scheduled tribe & .12 & .11 & .0061 & .83 & .096 & .12 & -.023 & .45 \\
Literacy & .42 & .42 & .0015 & .93 & .38 & .39 & -.013 & .4 \\
Annual income & 41447 & 42791 & -1387 & .49 & 33554 & 35279 & -2186 & .31 \\
Annual consumption & 104607 & 95281 & 8543 & .4 & 74602 & 77148 & -3445 & .55 \\
Pay to work/enroll & .01 & .0095 & .0009 & .83 & .054 & .07 & -.016 & .24 \\
Pay to collect & .058 & .036 & .023 & .14 & .059 & .072 & -.008 & .81 \\
Ghost HHD & .031 & .017 & .014 & .12 & .012 & .0096 & .0018 & .76 \\
Time to collect & 157 & 169 & -7.3 & .63 & 94 & 112 & $-18^{* *}$ & .027 \\
Average Payment Delay & 29 & 23 & .22 & .93 & & & & \\
Payment delay deviation & 11 & 8.8 & -.42 & .77 & & & & \\
Official amount & 167 & 159 & 12 & .51 & & & & \\
Survey amount & 171 & 185 & -12 & .56 & & & & \\
Leakage & -4.4 & -26 & 25 & .15 & & & & \\
NREGS availability & .47 & .56 & $-.1^{* *}$ & .02 & & & & \\
HHD doing NREGS work & .41 & .41 & .0021 & .95 & & & & \\
\hline
\end{tabular}

This table presents outcome means from the household survey. Columns 3 and 6 report the difference in treatment and control means, while columns 4 and 8 report the p-value on the treatment indicator, all from simple regressions of the outcome with district fixed effects as the only controls. "BPL" is an indicator for households below the poverty line. "Pay to work/enroll" refers to bribes paid in order to obtain NREGS work or to start receiving SSP pension. "Pay to Collect" refers to bribes paid in order to receive payments. "Ghost HHD" is a household with a beneficiary who does not exist (confirmed by three neighbors) but is listed as receiving payment on official records. "Time to Collect" is the time taken on average to collect a benefit payment, including the time spent on unsuccessful trips to payment sites, in minutes. Standard errors are clustered at the mandal level. Statistical significance is denoted as: ${ }^{*} p<0.10,{ }^{* *} p<0.05,{ }^{* * *} p<0.01$ 
Table A.3: Attrition from and entry into sample frames

(a) NREGS

\begin{tabular}{lcc}
\hline & $(1)$ & $(2)$ \\
& $\begin{array}{c}\text { Attriters from } \\
\text { Baseline }\end{array}$ & $\begin{array}{c}\text { Entrants in } \\
\text { Endline }\end{array}$ \\
\hline Control & .024 & .059 \\
Treatment & .013 & .061 \\
p-value & .22 & .79 \\
\hline
\end{tabular}

(b) SSP

\begin{tabular}{lcc}
\hline & $(1)$ & $(2)$ \\
& $\begin{array}{c}\text { Attriters from } \\
\text { Baseline }\end{array}$ & $\begin{array}{c}\text { Entrants in } \\
\text { Endline }\end{array}$ \\
\hline Control & .097 & .16 \\
Treatment & .097 & .17 \\
p-value & .95 & .36 \\
\hline
\end{tabular}

These tables compare the entire NREGS sample frame - i.e., all jobcard holders - and the entire SSP beneficiary frame across treatment and control mandals. Column 1 presents the proportion of NREGS jobcards and SSP beneficiaries that dropped out of the sample frame after baseline, while column 2 presents the proportion that entered the sample frame at endline. Row 3 reports the p-value of the difference between treatment and control.

Table A.4: Endline number of jobcards

\begin{tabular}{lcc}
\hline & \multicolumn{2}{l}{ Endline \# of Jobcards } \\
\cline { 2 - 3 } & $(1)$ & $(2)$ \\
\hline Treatment & 7.9 & 5 \\
& $(7.7)$ & $(7.4)$ \\
District FE & Yes & Yes \\
\hline Baseline Level & Yes & Yes \\
Adj R-squared & .97 & .97 \\
Control Mean & 664 & 675 \\
N. of cases & 2924 & 880 \\
Level & GP & GP \\
\hline
\end{tabular}

This table examines whether treatment led to any changes in the number of NREGS jobcards at the GP-level between baseline (2010) and endline (2012). It uses data from the full jobcard data frame in treatment and control mandals. Column 1 includes all GPs within study mandals. Column 2 shows only GPs sampled for our household survey. Standard errors clustered at mandal level in parentheses. 


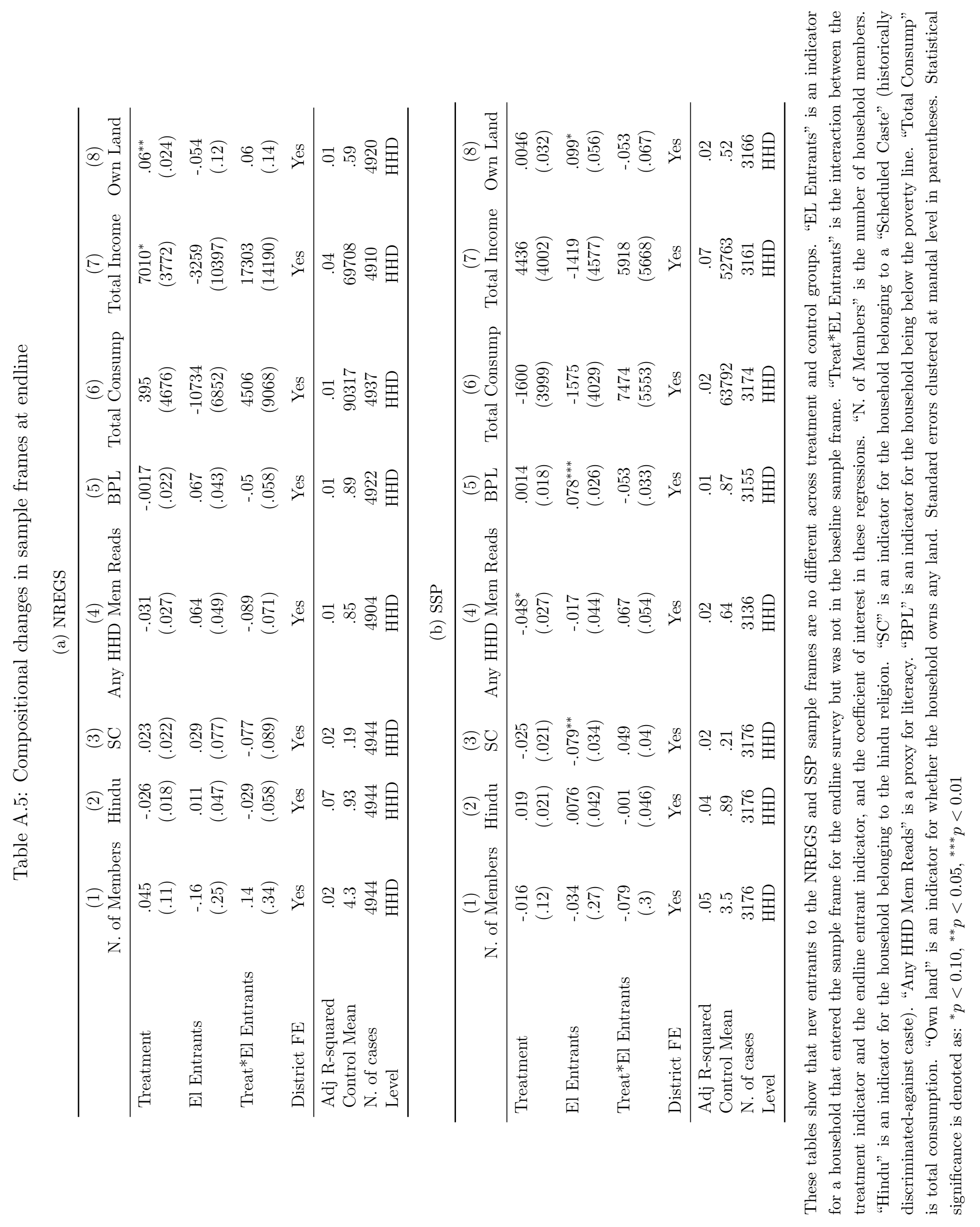




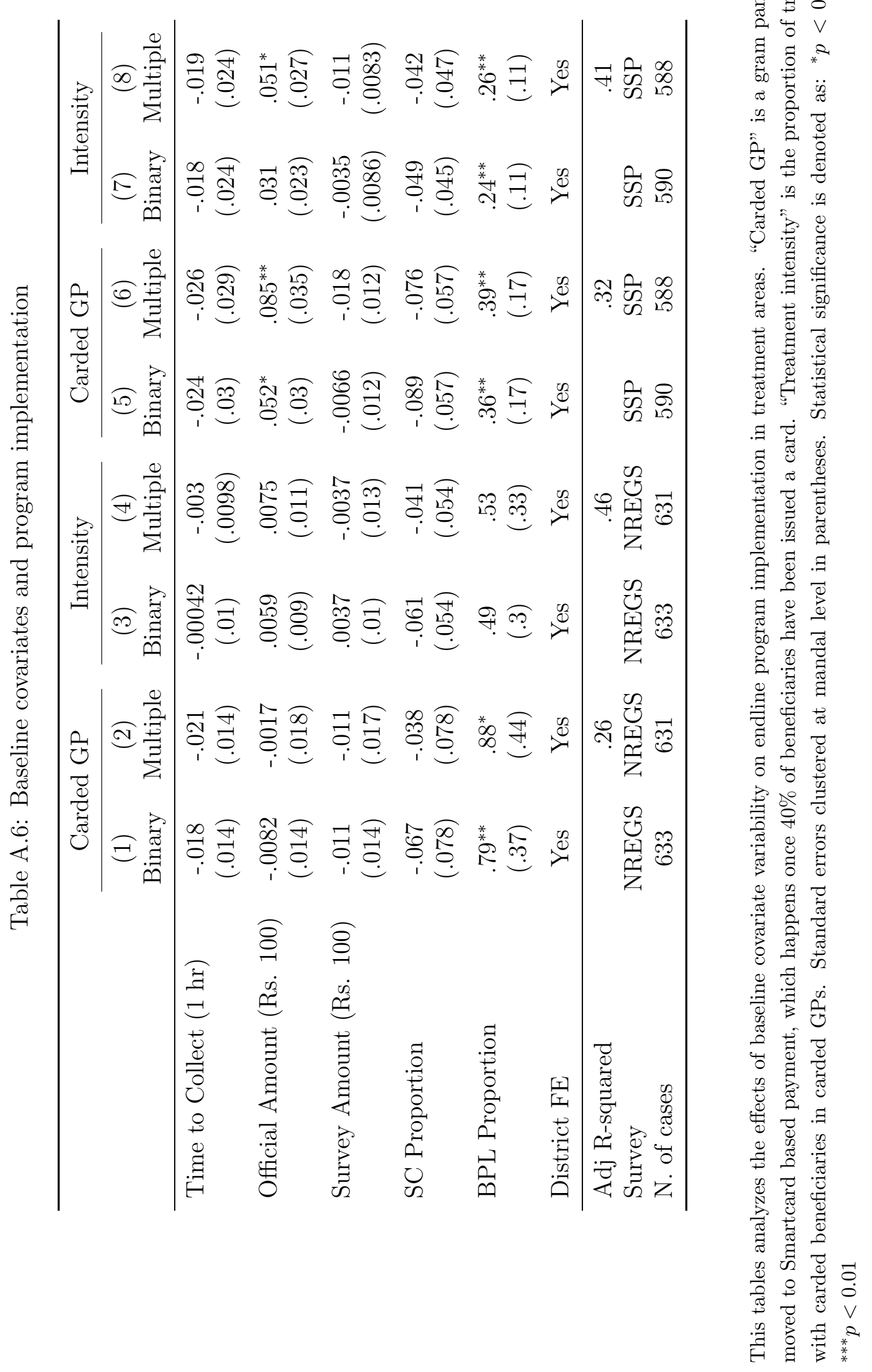


Table A.7: Correlates of owning a Smartcard

\begin{tabular}{lccccc}
\hline & \multicolumn{2}{c}{ NREGS } & & \multicolumn{2}{c}{ SSP } \\
\cline { 2 - 3 } \cline { 5 - 6 } & $(1)$ & $(2)$ & & $(3)$ & $(4)$ \\
& Binary & Multiple & Binary & Multiple \\
\hline Income (Rs. 10,000) & $-.0029^{* *}$ & $-.0028^{* *}$ & & .00047 & -.000023 \\
& $(.0014)$ & $(.0013)$ & & $(.0017)$ & $(.0017)$ \\
Consumption (Rs. 10,000) & -.0014 & -.001 & & .0014 & .0014 \\
& $(.0012)$ & $(.0012)$ & & $(.0021)$ & $(.0022)$ \\
Official amount (Rs. 100) & $.004^{* * *}$ & $.0042^{* * *}$ & .0003 & $9.6 \mathrm{e}-06$ \\
& $(.00082)$ & $(.00081)$ & & $(.0028)$ & $(.0028)$ \\
SC & $.071^{*}$ & $.079^{* *}$ & .019 & .021 \\
& $(.037)$ & $(.035)$ & & $(.028)$ & $(.029)$ \\
Female & $.039^{* *}$ & $.042^{* *}$ & & -.018 & -.017 \\
& $(.017)$ & $(.017)$ & & $(.023)$ & $(.023)$ \\
District FE & Yes & Yes & Yes & Yes \\
\hline Adj R-squared & & .27 & & .21 \\
Dep Var Mean & .47 & .47 & & .73 & .73 \\
N. of cases & 5269 & 5259 & & 1900 & 1898 \\
Level & Indiv. & Indiv. & Indiv. & Indiv. \\
\hline
\end{tabular}

This tables analyzes how endline covariates predict which individuals have or use a Smartcard within gram panchayats that have moved to Smartcard based payments ("Carded GPs"). Column 1 shows coefficients from binary regressions, with each covariate regressed separately. Column 2 runs one single regression with all covariates. "Income (Rs. 10,000)" is household income with units as $1=$ Rs. 10,000. "Consumption (Rs. 10,000)" is household consumption. "Land value (Rs. 10,000)" is household land value. "NREGS amount (Rs. 1,000)" is household NREGS income during the study period. "SC" is a dummy for whether household is Scheduled Caste. Standard errors clustered at mandal level in parentheses. Statistical significance is denoted as: ${ }^{*} p<0.10,{ }^{* *} p<0.05,{ }^{* * *} p<0.01$ 
Table A.8: NREGS employment in June

\begin{tabular}{lcccccccc}
\hline & \multicolumn{2}{c}{ Days worked } & & \multicolumn{2}{c}{ Hours worked } & & \multicolumn{2}{c}{ Hourly wage } \\
\cline { 2 - 3 } \cline { 8 - 9 } & $(1)$ & $(2)$ & & $(3)$ & $(4)$ & & $(5)$ & $(6)$ \\
\hline Treatment & .92 & .84 & & 5.5 & 5 & & .38 & .52 \\
& $(.66)$ & $(.64)$ & & $(3.4)$ & $(3.3)$ & & $(.77)$ & $(.8)$ \\
BL GP Mean & & $.14^{* * *}$ & & & $.14^{* * *}$ & & .022 \\
& & $(.042)$ & & $(.041)$ & & $(.037)$ \\
District FE & Yes & Yes & & Yes & Yes & & Yes & Yes \\
\hline Adj R-squared & .09 & .10 & & .11 & .11 & & .03 & .03 \\
Control Mean & 8.2 & 8.2 & & 42 & 42 & & 17 & 17 \\
N. of cases & 10567 & 10494 & & 10567 & 10494 & & 6960 & 6605 \\
Survey & NREGS & NREGS & & NREGS & NREGS & NREGS & NREGS \\
\hline
\end{tabular}

This table analyzes beneficiary level NREGS employment outcomes during the study period (baseline in 2010 - May 31 to July 4; endline in 2012 - May 28 to July 15). "Days worked" and "hours worked" refer to days and hours worked on NREGS project, while "hourly wage" is amount earned divided by total number of hours worked in the study period. Standard errors clustered at mandal level in parentheses. Statistical significance is denoted as: ${ }^{*} p<0.10,{ }^{* *} p<0.05,{ }^{* * *} p<0.01$ 
Table A.9: Adjusted earnings regressions

(a) NREGS

\begin{tabular}{lcccccccc}
\hline & \multicolumn{2}{c}{ Official } & & \multicolumn{2}{c}{ Survey } & & \multicolumn{2}{c}{ Leakage } \\
\cline { 2 - 3 } & $(1)$ & $(2)$ & & $(3)$ & $(4)$ & & $(5)$ & $(6)$ \\
\hline Treatment & 9.7 & 2.6 & & 33 & 32 & & -23 & -28 \\
& $(25)$ & $(24)$ & & $(21)$ & $(20)$ & & $(21)$ & $(20)$ \\
BL GP Mean & & $.16^{* * *}$ & &..$^{* * *}$ & & $.13^{* * *}$ \\
& & $(.025)$ & & $(.037)$ & & $(.033)$ \\
District FE & Yes & Yes & & Yes & Yes & & Yes & Yes \\
\hline Adj R-squared & .03 & .05 & & .06 & .07 & & .06 & .07 \\
Control Mean & 260 & 260 & & 180 & 180 & & 80 & 80 \\
N. of cases & 5179 & 5143 & & 5179 & 5143 & & 5179 & 5143 \\
\hline
\end{tabular}

(b) SSP

\begin{tabular}{|c|c|c|c|c|c|c|}
\hline & \multicolumn{2}{|c|}{ Official } & \multicolumn{2}{|c|}{ Survey } & \multicolumn{2}{|c|}{ Leakage } \\
\hline & (1) & $(2)$ & (3) & (4) & $(5)$ & $(6)$ \\
\hline Treatment & $\begin{array}{c}.83 \\
(6.3)\end{array}$ & $\begin{array}{l}-1.7 \\
(6.5)\end{array}$ & $\begin{array}{c}7 \\
(7.1)\end{array}$ & $\begin{array}{c}5.6 \\
(7.5)\end{array}$ & $\begin{array}{c}-7.8^{*} \\
(4.6)\end{array}$ & $\begin{array}{l}-7.6 \\
(4.9)\end{array}$ \\
\hline BL GP Mean & & $\begin{array}{c}.074 \\
(.082)\end{array}$ & & $\begin{array}{c}.031 \\
(.057)\end{array}$ & & $\begin{array}{c}.07 \\
(.072)\end{array}$ \\
\hline District FE & Yes & Yes & Yes & Yes & Yes & Yes \\
\hline Adj R-squared & .01 & .01 & .00 & .00 & .01 & .01 \\
\hline Control Mean & 242 & 242 & 222 & 222 & 20 & 20 \\
\hline N. of cases & 2239 & 2034 & 2239 & 2034 & 2239 & 2034 \\
\hline
\end{tabular}

The regressions include all sampled beneficiaries who were a) found by survey team to match official record or b) listed in official records but confirmed as "ghost" beneficiary as described in Table 3 . In panel (a), each observation refers to householdlevel average weekly amounts for NREGS work done during the study period (baseline in 2010 - May 31 to July 4; endline in 2012 - May 28 to July 15). "Official" refers to amounts paid as listed in official muster records, scaled by the average number of jobcards per household in the district. "Survey" refers to payments received as reported by beneficiaries. "Leakage" is the difference between these two amounts. In panel (b), each observation refers to the average SSP monthly amount for the period May, June, and July; the sample is restricted to households who only had a single beneficiary. "Official" refers to amounts paid as listed in official disbursement records. "Survey" refers to payments received as reported by beneficiaries. "Leakage" is the difference between these two amounts. Standard errors clustered at mandal level in parentheses. Statistical significance is denoted as: ${ }^{*} p<0.10,{ }^{* *} p<0.05,{ }^{* * *} p<0.01$ 


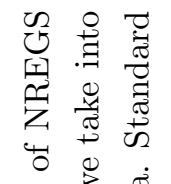

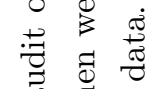

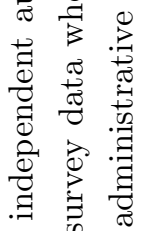

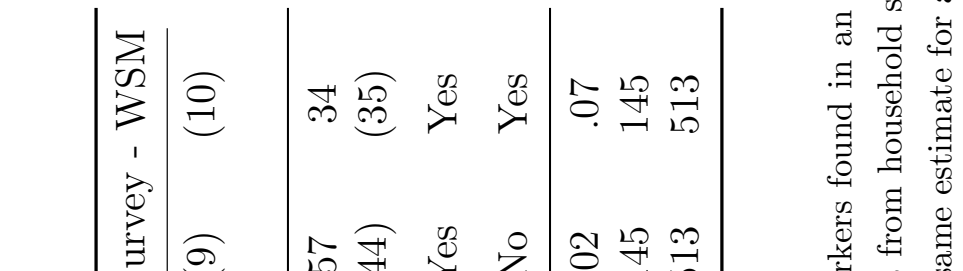

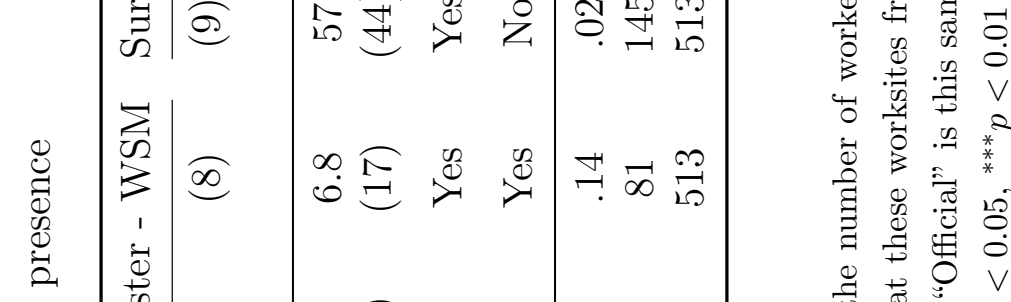

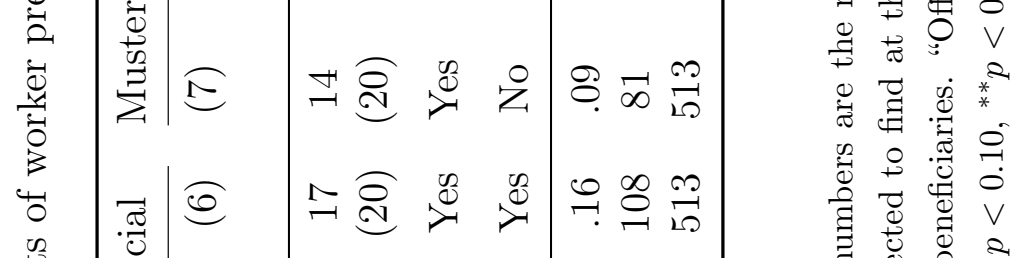

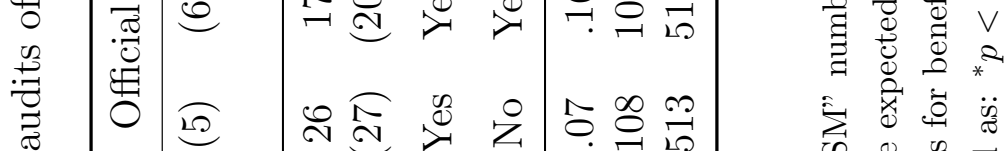

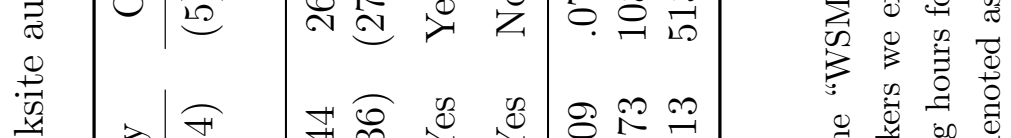

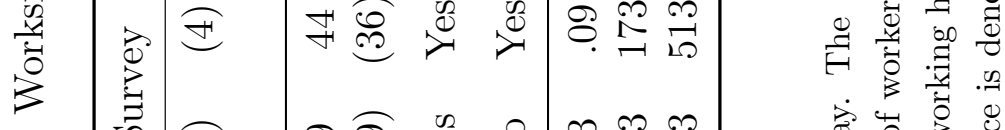

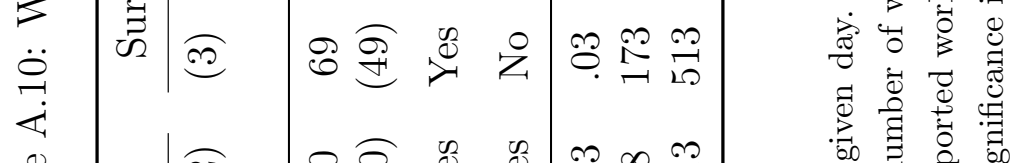

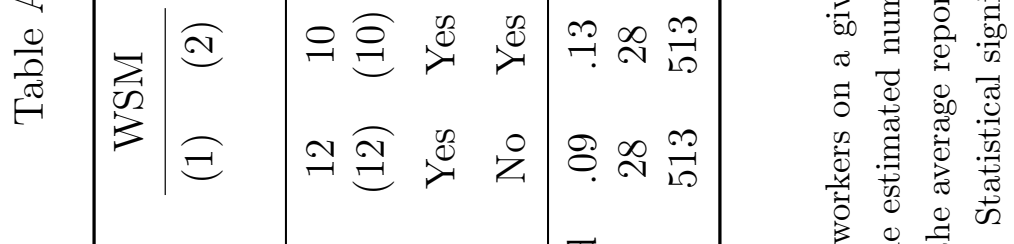

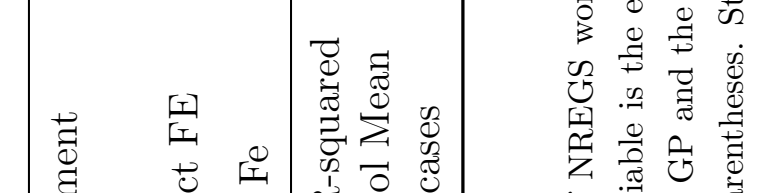

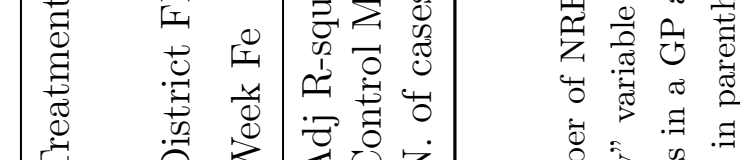

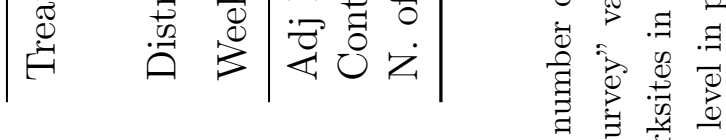

$$
\begin{aligned}
& \text { ठ } \\
& \text { 苛㟧 } \\
& \text { 实 }
\end{aligned}
$$

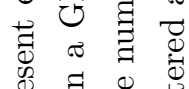

$$
\begin{aligned}
& \text { 可 } \\
& \text { 丞 }
\end{aligned}
$$

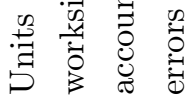


Table A.11: Hawthorne effects on measurement

\begin{tabular}{|c|c|c|c|c|c|c|}
\hline & \multirow{2}{*}{$\frac{\mathrm{WSM}}{(1)}$} & \multicolumn{4}{|c|}{ Official } & \multirow{2}{*}{$\frac{\text { Survey }}{(6)}$} \\
\hline & & (2) & (3) & (4) & (5) & \\
\hline HHD Survey in GP & $\begin{array}{c}-3.4 \\
(8)\end{array}$ & $\begin{array}{c}10 \\
(34)\end{array}$ & $\begin{array}{l}-4.8 \\
(33)\end{array}$ & & & \\
\hline WSM in GP & & $\begin{array}{c}7.5 \\
(31)\end{array}$ & $\begin{array}{l}-13 \\
(28)\end{array}$ & $\begin{array}{c}3 \\
(42)\end{array}$ & $\begin{array}{l}-17 \\
(37)\end{array}$ & $\begin{array}{c}113 \\
(106)\end{array}$ \\
\hline WSM Survey in Week & & $\begin{array}{l}-52 \\
(51)\end{array}$ & $\begin{array}{l}-71 \\
(52)\end{array}$ & $\begin{array}{c}-31 \\
(39)\end{array}$ & $\begin{array}{c}-39 \\
(39)\end{array}$ & $\begin{array}{c}34 \\
(84)\end{array}$ \\
\hline Recon Survey in Week & & $\begin{array}{c}12 \\
(69)\end{array}$ & $\begin{array}{c}-.8 \\
(68)\end{array}$ & $\begin{array}{c}45 \\
(52)\end{array}$ & $\begin{array}{c}40 \\
(51)\end{array}$ & $\begin{array}{c}45 \\
(89)\end{array}$ \\
\hline District FE & Yes & Yes & Yes & Yes & Yes & Yes \\
\hline Week Fe & Yes & Yes & Yes & Yes & Yes & Yes \\
\hline BL GP Value & No & No & Yes & No & Yes & Yes \\
\hline GP Size FE & No & Yes & Yes & No & No & No \\
\hline Adj R-squared & .17 & & & & & \\
\hline Control Mean & 48 & 758 & 758 & 755 & 755 & 1170 \\
\hline Level & Week & Week & Week & Week & Week & Week \\
\hline Sample & WSM & All & All & HHD \& WSM & HHD \& WSM & HHD \\
\hline N. of cases & 682 & 52311 & 52311 & 7728 & 7728 & 6153 \\
\hline
\end{tabular}

This table analyzes possible Hawthorne effects from the assorted treatment arms. Each cell represents a separate regression of the effect on the data source (column) from the survey type (row). Units are number of days worked in a GP per week. "HHD Survey in GP" is the being surveyed by the household survey. "WSM in GP" is being surveyed by the work site audit. Control mean represents the area with no survey. "WSM Survey in Week" is whether the work site audit happened in that specific week. "Recon Survey in week" is whether an enumerator to map the worksites in that specific week. Sample of "All" refers to all GPs in our study districts. Standard errors clustered at mandal level in parentheses. Statistical significance is denoted as: ${ }^{*} p<0.10,{ }^{* *} p<0.05,{ }^{* * *} p<0.01$ 
(a) Status Quo

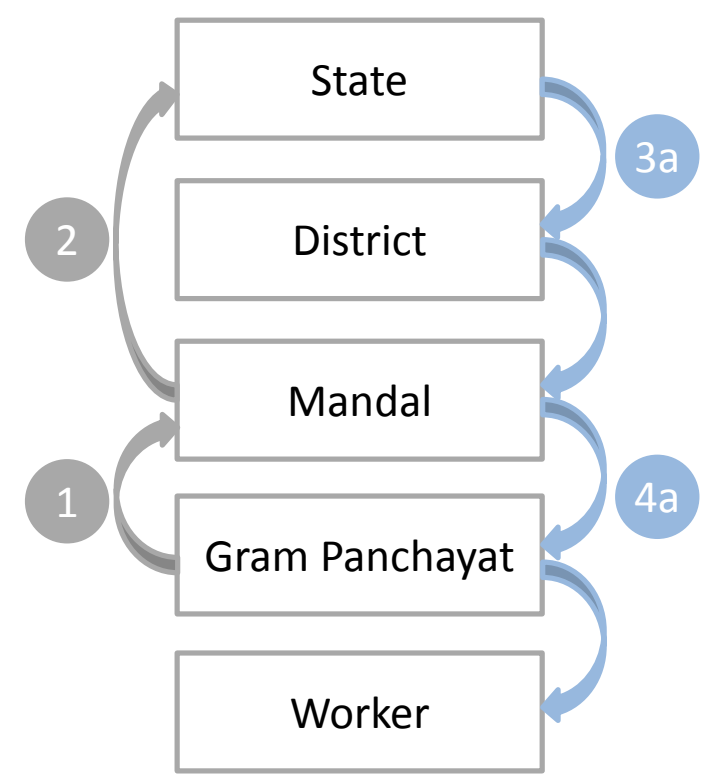

(b) Smartcard-enabled

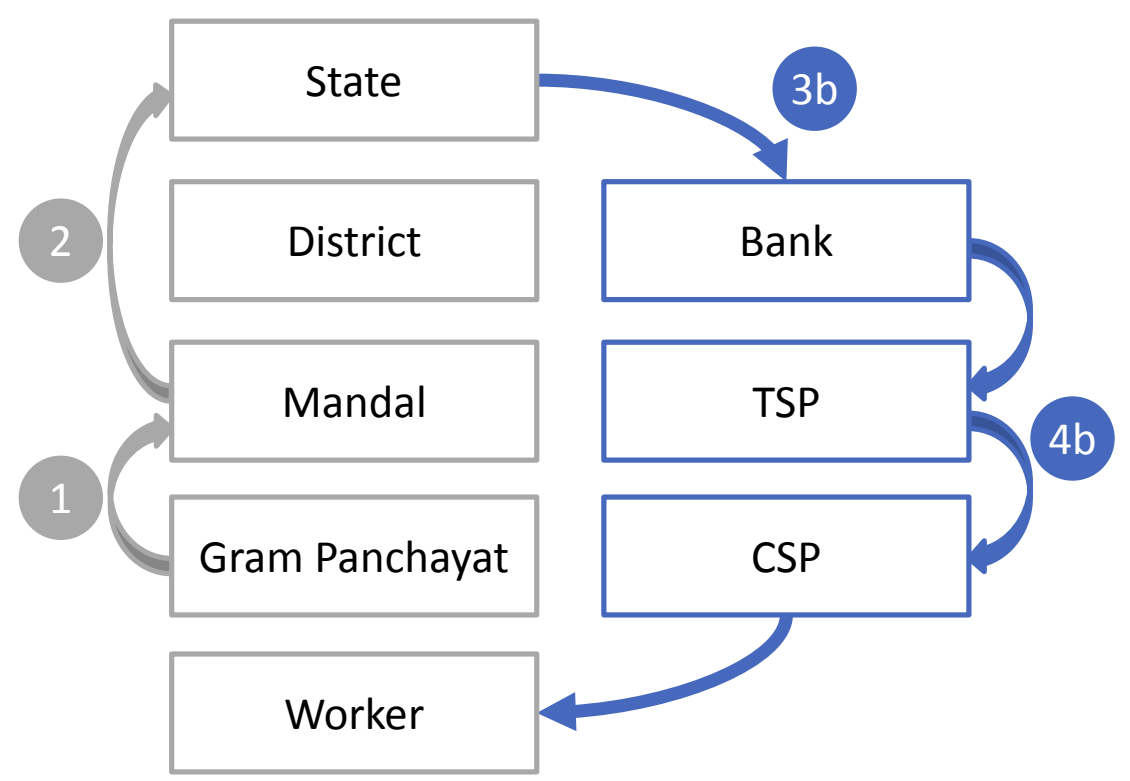

Figure A.1: Comparison of treatment and control payment systems

"TSP" is a Technology Service Provider, a firm contracted by the bank to handle details of electronic transfers. "CSP" is a Customer Service Provider, from whom beneficiaries receive cash payments after authentication. In both systems, (1) paper muster rolls are maintained by the GP and sent to the mandal computer center, and (2) the digitized muster roll data is sent to the state financial system. In the status quo model, (3a) the money is transferred electronically from state to district to mandal, and (4a) the paper money is delivered to the GP (typically via post office) and then to the workers. In the Smartcard-enabled system, (3b) the money is transferred electronically from the state to the bank, to the TSP, and finally to the CSP, and (4b) the CSP delivers the cash and receipts to authenticated recipients. 


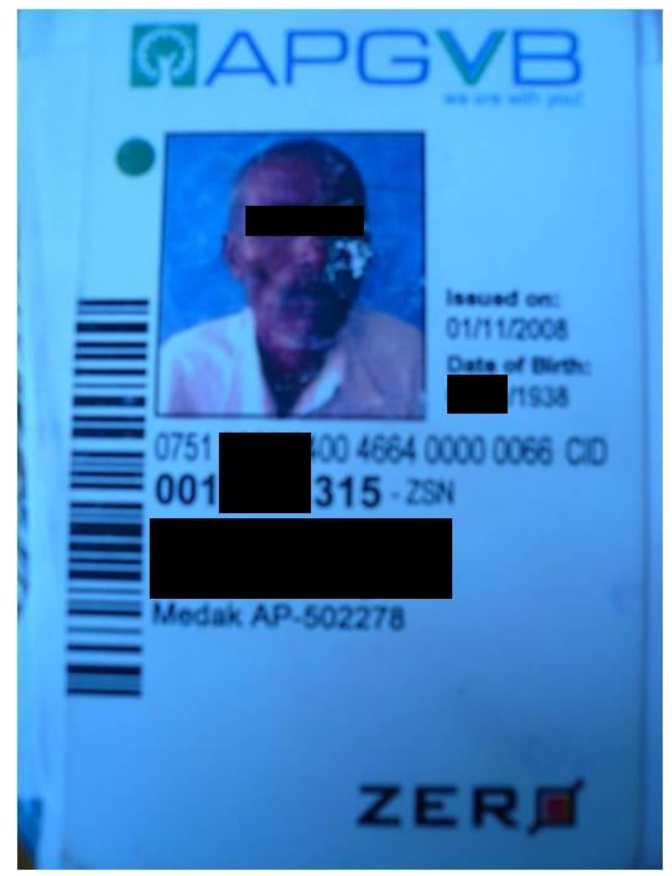

(a) Sample Smartcard

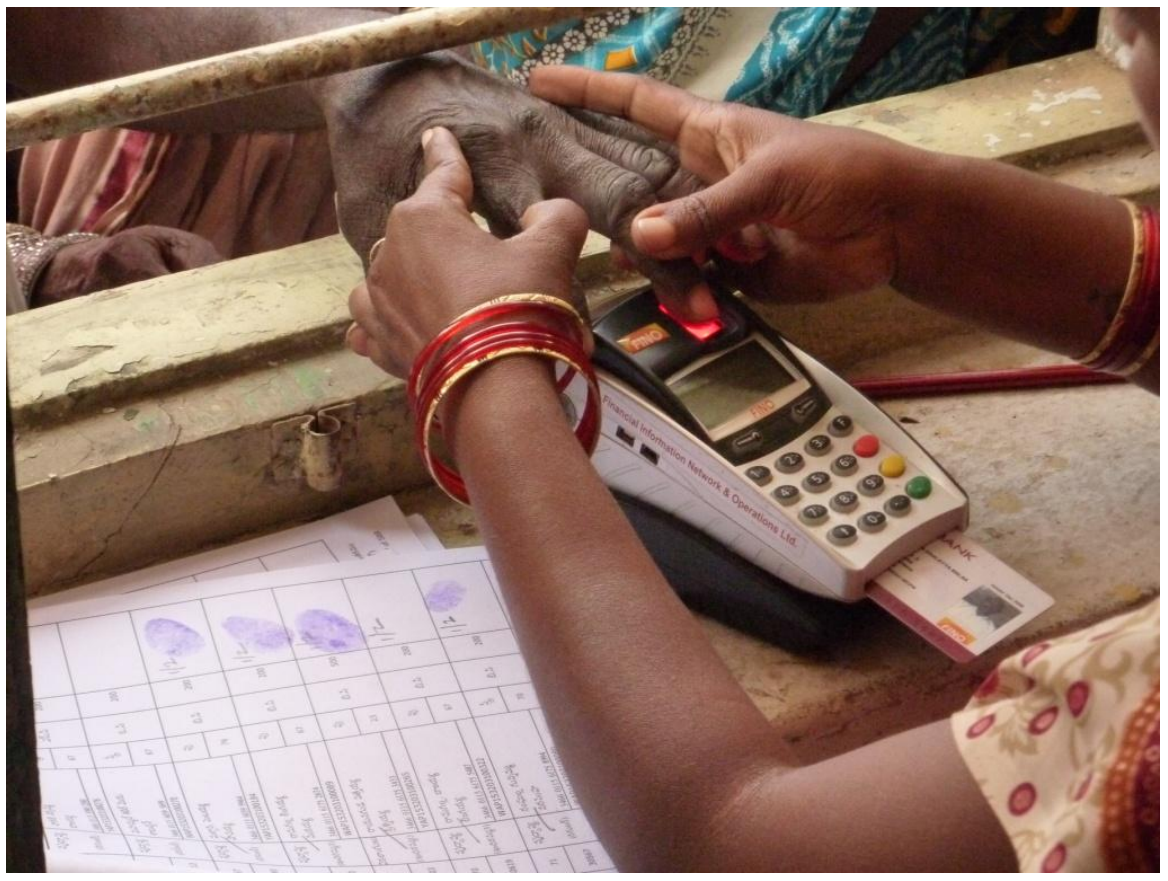

(b) Point-of-Service device

Figure A.2: The technology 


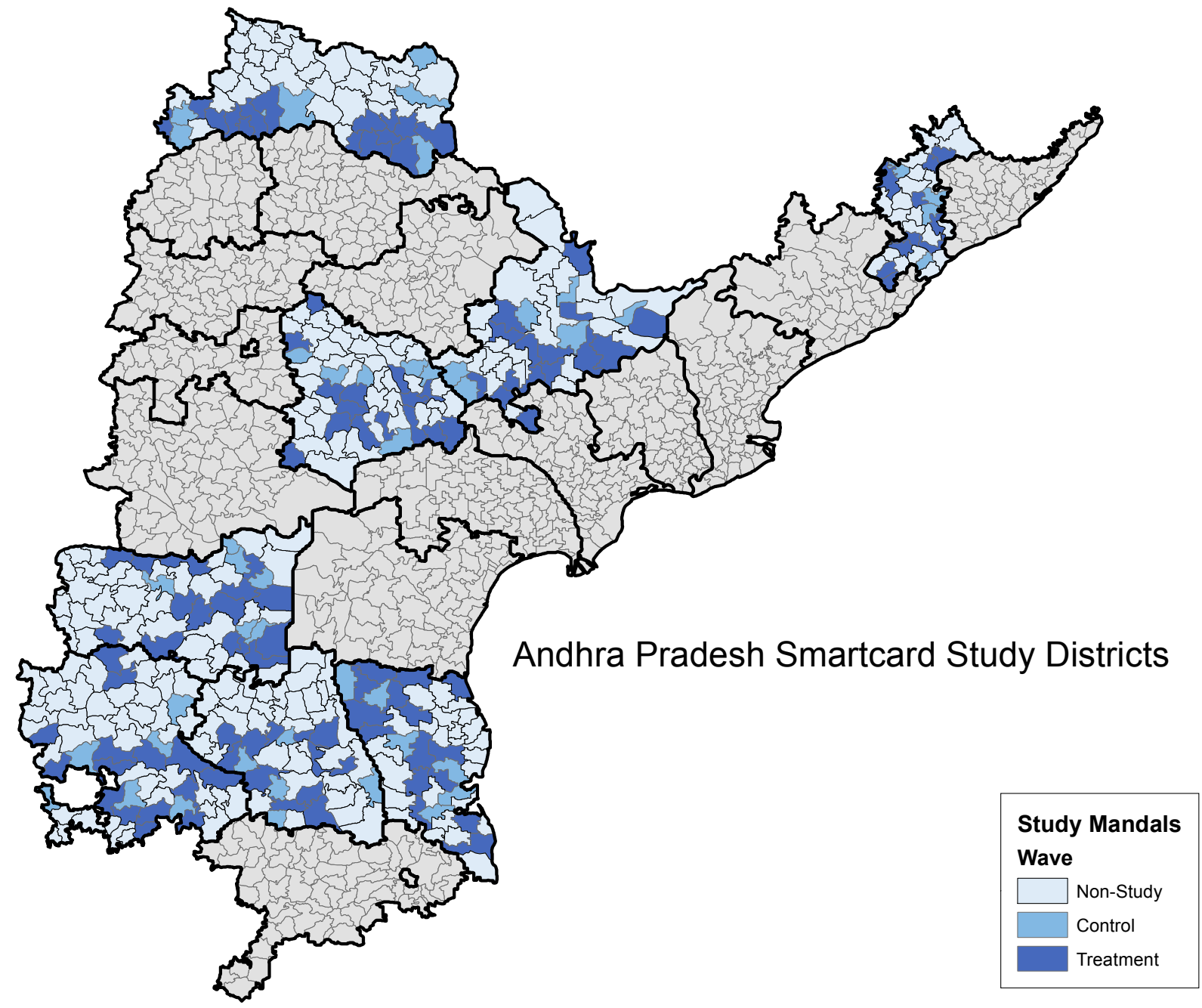

Figure A.3: Study districts with treatment and control mandals

This map shows the 8 study districts and the assignment of mandals (sub-districts) to treatment and control groups. Mandals were randomly assigned to one of three waves: 113 to wave 1,195 to wave 2 , and 45 to wave 3 . Wave 2 was created as a buffer to maximize the time between program rollout in treatment and control waves; our study does not use data from these mandals. Randomization was stratified by revenue division (an administrative unit between the district and mandal) and by a principal component of mandal characteristics including population, literacy, Scheduled Caste and Tribe proportion, NREGS jobcards, NREGS peak employment rate, proportion of SSP disability recipients, and proportion of other SSP pension recipients. 